\title{
Killing two birds with one stone: dual blockade of integrin and FGF signaling through targeting syndecan-4 in postoperative capsular opacification
}

\author{
Yingyan Qin ${ }^{1,3}$, Yi Zhu ${ }^{1,2,3}$, Furong Luo ${ }^{1}$, Chuan Chen ${ }^{1,2}$, Xiaoyun Chen ${ }^{1}$ and Mingxing Wu*,
}

The most common complication after cataract surgery is postoperative capsular opacification, which includes anterior capsular opacification (ACO) and posterior capsular opacification (PCO). Increased adhesion of lens epithelial cells (LECs) to the intraocular lens material surface promotes ACO formation, whereas proliferation and migration of LECs to the posterior capsule lead to the development of PCO. Cell adhesion is mainly mediated by the binding of integrin to extracellular matrix proteins, while cell proliferation and migration are regulated by fibroblast growth factor (FGF). Syndecan-4 (SDC-4) is a co-receptor for both integrin and FGF signaling pathways. Therefore, SDC-4 may be an ideal therapeutic target for the prevention and treatment of postoperative capsular opacification. However, how SDC-4 contributes to FGF-mediated proliferation, migration, and integrinmediated adhesion of LECs is unclear. Here, we found that downregulation of SDC-4 inhibited FGF signaling through the blockade of ERK1/2 and PI3K/Akt/mTOR activation, thus suppressing cell proliferation and migration. In addition, downregulation of SDC-4 suppressed integrin-mediated cell adhesion through inhibiting focal adhesion kinase (FAK) phosphorylation. Moreover, SDC-4 knockout mice exhibited normal lens morphology, but had significantly reduced capsular opacification after injury. Finally, SDC-4 expression level was increased in the anterior capsule LECs of age-related cataract patients. Taken together, we for the first time characterized the key regulatory role of SDC-4 in FGF and integrin signaling in human LECs, and provided the basis for future pharmacological interventions of capsular opacification.

Cell Death and Disease (2017) 8, e2920; doi:10.1038/cddis.2017.315; published online 13 July 2017

Cataract remains the leading cause of vision loss worldwide, accounting for 11 million cases of blindness and 35 million cases of visual impairment every year. ${ }^{1,2}$ Currently, phacoemulsification with intraocular lens (IOL) implantation is the most effective treatment for cataract. However, this procedure has many postoperative complications. ${ }^{3,4}$ The most common complication after cataract surgery is postoperative capsular opacification, which includes anterior capsular opacification (ACO) and posterior capsular opacification (PCO). Both ACO and PCO can greatly affect the visual quality of cataract patients. ACO usually develops faster than PCO and may lead to IOL decentration, anterior capsule shrinkage, or hinder the examination of the peripheral fundus. ${ }^{5} \mathrm{PCO}$ is more common than ACO, with an incidence of $20 \%$ to $40 \%$ in adult patients and $100 \%$ in children. ${ }^{6}$ Unlike ACO, PCO can involve the central visual axis, and it may, therefore, severely compromise visual acuity. Currently, the only effective treatment for PCO is $\mathrm{Nd}$ :YAG laser capsulotomy, which may induce further complications.

As lens epithelial cells (LECs) are distributed only underneath the anterior capsule, $\mathrm{ACO}$ and $\mathrm{PCO}$ have distinct pathogenic mechanisms. ACO is initially triggered by the adhesion of residual LECs and inflammatory cells in the aqueous humor onto the intraocular lens (IOL) surface and the subsequent proliferation and epithelial-mesenchymal transition (EMT) of LECs. ${ }^{7}$ In contrast, the first step of PCO is the migration of LECs from the anterior capsule to the posterior capsule. ${ }^{6}$ In the past decades, many attempts have been made to reduce ACO and PCO. One effective approach to reduce ACO is inhibiting the adhesion of cells onto the IOL surface. Notably, among all IOL materials, the most widely used hydrophobic acrylic IOLs have the highest incidence of ACO formation, as protein and cells can easily adhere to hydrophobic surfaces. ${ }^{8}$ Studies from our group and others have reported that hydrophilic surface modification of IOLs can significantly increase protein and cell repellence, thus preventing $\mathrm{ACO} .^{9,10}$ On the other hand, $\mathrm{PCO}$ can be suppressed through blocking the migration and proliferation of LECs, which can be achieved by applying cytotoxic drugs or sharpening the optic edge of the IOLs. ${ }^{11}$ However, preventative approaches of $\mathrm{ACO}$ and $\mathrm{PCO}$ are contradictory. A reduction in LEC adhesion force may promote LEC proliferation and migration, resulting in increased risk of $\mathrm{PCO}$ development. ${ }^{12,13}$

Here, we attempted to identify a key regulator in the pathogenesis of capsular opacification that suppresses both ACO and PCO when targeted. Cell adhesion is mainly mediated by integrin signaling. Shortly after IOL implantation, extracellular matrix (ECM) proteins, such as fibronectin, laminin, and collagen, will adhere onto the IOL surface. ECM

\footnotetext{
${ }^{1}$ State key Laboratory of Ophthalmology, Zhongshan Ophthalmic Center, Sun Yat-sen University, Guangzhou 510060, China and ${ }^{2}$ Department of Molecular and Cellular Pharmacology, University of Miami Miller School of Medicine, Miami, FL 33136, USA

*Corresponding author: M Wu, Zhongshan Ophthalmic Center, Sun Yat-sen University, 54 South Xianlie Road, Guangzhou 510060, China. Tel: +86 02087330293 ; Fax: +86 02087333271 ; E-mail: wumingx@mail.sysu.edu.cn

${ }^{3}$ These authors contributed equally to this work.

Received 1.3.17; revised 3.6.17; accepted 5.6.17; Edited by A Stephanou
} 
proteins contain an Arg-Gly-Asp (RGD) sequence that can be recognized by integrin, which recruits and activates focal adhesion kinase (FAK), initiating cell adhesion. ${ }^{14}$ In contrast, cell migration and proliferation are promoted by various cytokines and growth factors. ${ }^{15}$ Fibroblast growth factor (FGF) is one of the most potent growth factors that regulates a

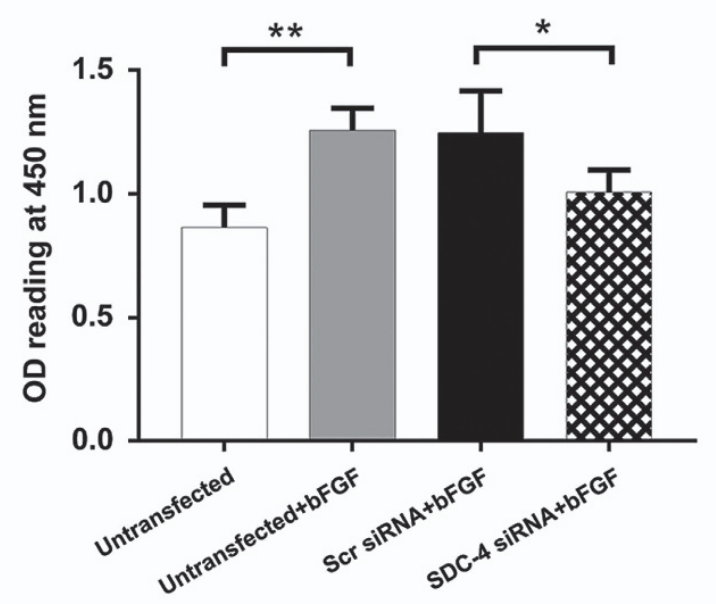

b bFGF $\frac{\text { Untransfected }}{-} \frac{\text { Scr siRNA }}{-} \frac{\text { SDC-4 siRNA }}{-}+\frac{+}{+}$

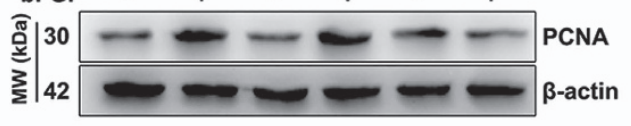

c
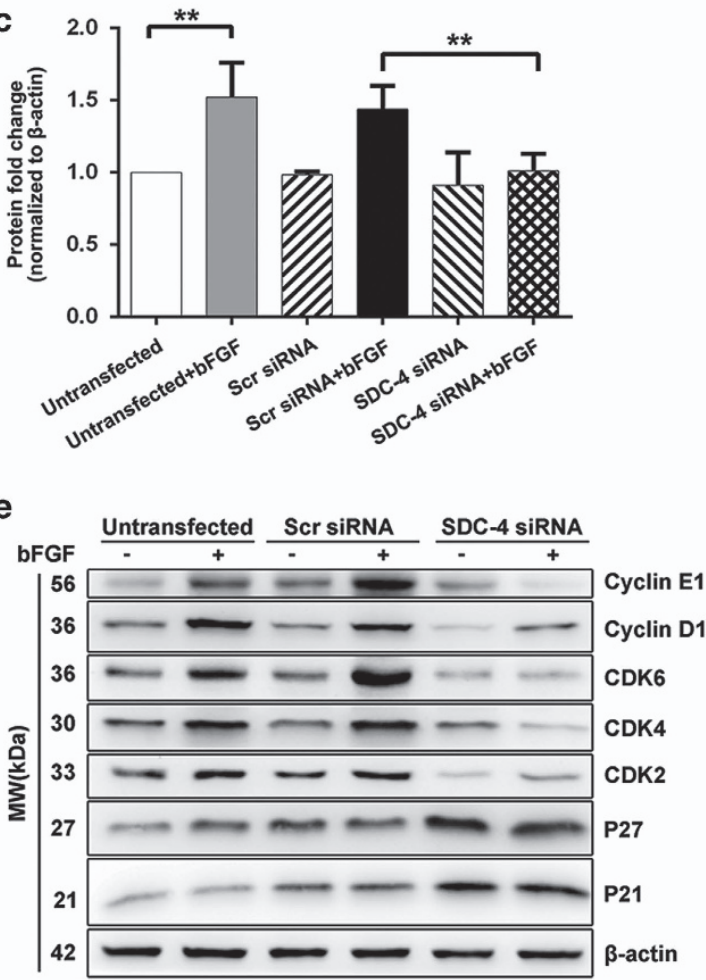

f

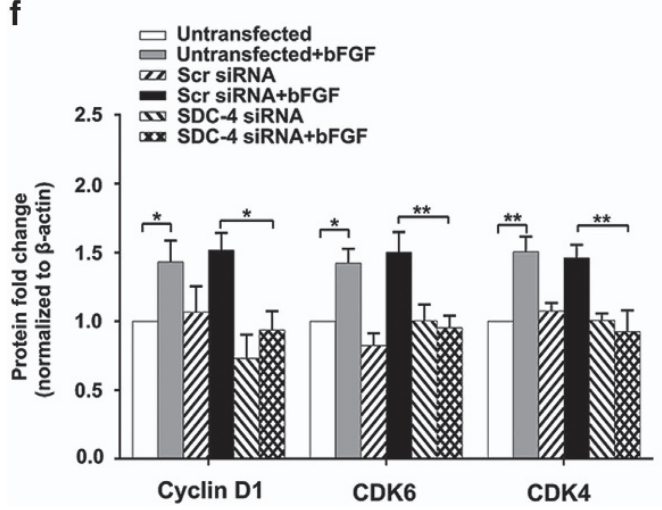

$\begin{array}{ll}\text { g } & \\ & \\ & \\ & .0\end{array}$

$\square$ Untransfected Untransfected+bFGF Ce Scr siRNA - Scr SiRNA+bFGF

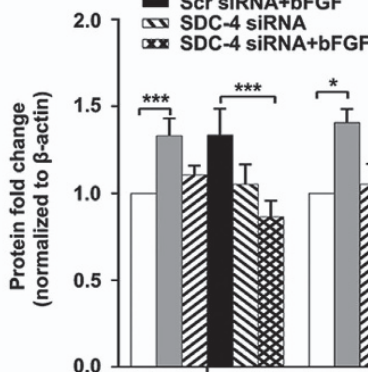

Cyclin E1<smiles>C1CCC1</smiles>

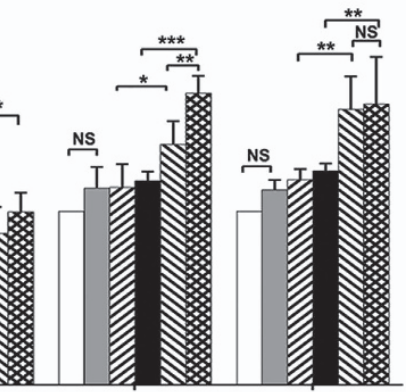

P27

P21

Figure 1 Downregulation of SDC-4 suppressed FGF-induced cell proliferation. (a) LECs were transfected with scrambled/SDC-4 siRNA for $48 \mathrm{~h}$. Cell proliferation was analyzed by CCK-8 assay after $50 \mathrm{ng} / \mathrm{ml}$ bFGF treatment for $48 \mathrm{~h}$. Data represent the mean \pm S.D. ${ }^{*} P<0.05,{ }^{* *} P<0.01, n=3$. (b) LECs were transfected with scrambled/SDC-4 siRNA and treated with/without $50 \mathrm{ng} / \mathrm{ml}$ bFGF for $48 \mathrm{~h}$. Western blot analysis was performed to probe for PCNA ( $30 \mathrm{kDa})$. $\beta$-actin $(42 \mathrm{kDa})$ was used as an internal control. (c) Quantification of the PCNA expression level. The fold change relative to the level in the untransfected group is displayed. Data represent the mean \pm S.D. ${ }^{* \star} P<0.01, n=3$. (d) LECs were transfected with scrambled/SDC-4 siRNA and treated with/without $50 \mathrm{ng} / \mathrm{ml}$ bFGF for $48 \mathrm{~h}$. Cell cycle analysis was performed by flow cytometry. (e) LECs were transfected with scrambled/SDC-4 siRNA and treated with/without $50 \mathrm{ng} / \mathrm{ml}$ bFGF for $48 \mathrm{~h}$. Western blot analysis was performed to probe for cyclin E1 (56 kDa), cyclin D1 (36 kDa), CDK6 (36 kDa), CDK4 (30 kDa), CDK2 (33 kDa), P27 (27 kDa), and P21 (21 kDa). (f and g) Quantification of the protein expression levels in e. The fold change relative to the level in the untransfected group is displayed. Data represent the mean \pm S.D. ${ }^{\star} P<0.05,{ }^{\star \star} P<0.01,{ }^{* \star \star} P<0.001$; NS, not significant, $n=3$ 
cell migration and proliferation. The FGF family comprises two prototypic members, acidic FGF (aFGF) and basic FGF (bFGF), as well as 21 related polypeptide growth factors. ${ }^{16}$ Among them, bFGF is considered as the most important regulator during LECs proliferation and differentiation, and is significantly upregulated in aqueous humor after cataract surgery. ${ }^{17}$ Mutations of the FGF receptor (FGFR) lead to aberrant cell growth and differentiation, resulting in developmental defects. ${ }^{18,19}$ Apparently, an ideal approach is to simultaneously inhibit FGF-mediated LEC proliferation and migration, as well as integrin-mediated cell adhesion. Intriguingly, integrin signaling and FGF signaling share a common co-receptor, syndecan-4 (SDC-4). ${ }^{20}$ SDC-4 is a transmembrane proteoglycan that is highly expressed on epithelial cells. ${ }^{21}$ Inhibition of SDC-4 expression significantly delayed wound healing through suppression of cell proliferation and migration. ${ }^{22}$ In contrast, SDC-4 overexpression enhanced wound closure in diabetic mice. ${ }^{23}$ In addition, SDC-4 is a widespread component of focal adhesion, and focal adhesion formation is increased upon SDC-4 overexpression. ${ }^{24,25}$ However, the role of SDC-4 in the proliferation, migration, and adhesion of LECs has not been fully elucidated.

Based on the essential co-regulatory role of SDC-4 in both FGF and integrin signaling, we hypothesize that targeting SDC-4 may effectively inhibit FGF and integrin signaling simultaneously, thus suppressing the formation of capsular opacification. In this study, we applied both in vitro and in vivo models to characterize the function of SDC-4 in the FGF and integrin signaling pathways in human LECs. Our study supported SDC-4 as a potential pharmacological target for preventative strategies against postoperative capsular opacification.

\section{Results}

SDC-4 downregulation suppressed FGF-induced cell proliferation through inhibition of the G1/S transition. To determine the role of SDC-4 in FGF signaling, we knocked down SDC-4 in LECs by using RNAi as previously described. ${ }^{26}$ We observed a significant downregulation of SDC-4 after SDC-4 siRNA transfection at both transcript and protein levels (Supplementary Figure 1). Then, we performed a CCK-8 assay to evaluate cell proliferation. It has been shown that bFGF is a potent inducer for LEC proliferation. ${ }^{27}$ Indeed, we found that $50 \mathrm{ng} / \mathrm{ml}$ bFGF promoted LEC proliferation, as the group treated with bFGF for $48 \mathrm{~h}$ had significantly higher optical density (OD) values than that of the untreated group $(1.257 \pm 0.091$ versus $0.863 \pm 0.091, P<0.01)$. SDC-4 knockdown (KD) suppressed the proliferative effect of bFGF, as the OD value of the SDC-4 siRNA-transfected group was significantly lower than that of the scrambled siRNAtransfected group after bFGF treatment for $48 \mathrm{~h}$ $(1.007 \pm 0.091$ versus $1.247 \pm 0.170, P<0.05$; Figure $1 \mathrm{a})$, with an inhibition rate of $19.2 \%$. We also normalized the OD value at $48 \mathrm{~h}$ to the OD value at $12 \mathrm{~h}$ to minimize the confounding factor of cell adhesion, and obtained comparable results (Supplementary Figure 2). Proliferating cell nuclear antigen (PCNA) is a cellular marker for proliferation. ${ }^{28}$ Consistently, we found that bFGF treatment for $48 \mathrm{~h}$ significantly upregulated the expression level of PCNA, which could be suppressed by SDC-4 KD (Figures $1 \mathrm{~b}$ and $\mathrm{c}$ ).

Inhibition of cell proliferation may result from an induction of apoptosis, suppression of cell cycle progression, or a combinatorial effect of both. ${ }^{29}$ We first assessed apoptosis by measuring the activation of caspase- 3 and caspase- 9 . No significant differences in the levels of caspase-3, caspase-9, or their respective cleaved products were observed after SDC-4 KD, suggesting that the reduction in cell viability after SDC-4 KD was not due to increased apoptosis (Supplementary Figure 3). Next, we evaluated the cell cycle distribution by flow cytometry. We found that bFGF increased the percentage of cells in the $S$ phase and reduced the percentage of cells in the G0/G1 phase. This bFGF-induced cell cycle progression can be suppressed by SDC-4 KD (Figure 1d). To further dissect how SDC-4 KD inhibited cells from entering into the $S$ phase, we evaluated the expression levels of key cell cycle regulators. The $\mathrm{G} 1 / \mathrm{S}$ transition requires the phosphorylation of retinoblastoma protein $(\mathrm{Rb})$, which is initiated by the cyclin D1-cyclin-dependent kinase (CDK)6/ CDK4 complex and completed by the cyclin E1-CDK2 complex. ${ }^{30}$ We found that treatment with $50 \mathrm{ng} / \mathrm{ml}$ bFGF for $48 \mathrm{~h}$ significantly increased the levels of cyclin E1, cyclin D1, CDK6, CDK4, and CDK2, which could be suppressed by SDC-4 KD (Figures 1e-g). In addition, SDC-4 KD upregulated the expression levels of P21 and P27 (Figures 1e and g), which act as CDK inhibitors and prevent the activation of cyclin E1-CDK2. ${ }^{31}$ We repeated these experiments in another wellestablished human lens epithelial cell line HLE-B3 and a human retinal pigment epithelial cell line ARPE-19, and obtained similar results(Supplementary Figures 4 and 5). Taken together, these data demonstrated that SDC-4 is required for the bFGF-promoted cell cycle progression.

SDC-4 downregulation inhibited FGF signaling through blocking downstream activation of PKCa, ERK1/2, and PI3K/Akt/mTOR. FGF promotes cell proliferation mainly through the extracellular signal-regulated kinase 1/2 (ERK1/2) pathway and the phosphatidylinositol 3-kinase (PI3K)/Akt/ mammalian target of rapamycin (mTOR) pathway. ${ }^{32}$ Phosphorylation of Akt leads to reduced expression of P21 and P27, ${ }^{33,34}$ whereas phosphorylation of ERK1/2 and S6 ribosomal protein (S6RP, a downstream effector of mTOR) increases expression of the cyclin D1-CDK6/CDK4 complex. ${ }^{35}$ Dephosphorylation of the SDC-4 cytoplasmic tail has been shown to increase the binding of phosphatidylinositol 4, 5-bisphosphate $\mathrm{PIP}_{2}$ to SDC-4 and subsequently upregulate and activate protein kinase $\mathrm{C} a(\mathrm{PKC} a)$, which is a potent activator of ERK1/2 and $\mathrm{Akt}^{20}$ Indeed, we found that bFGF significantly upregulated the expression level of PKCa, and this upregulation required SDC-4 (Figures $2 a$ and b). In addition, SDC-4 KD abrogated bFGF-induced ERK1/2, Akt, and S6RP phosphorylation (Figures 2c-f). Notably, we found that Gö6976, a PKC inhibitor, specifically suppressed phosphorylation of Akt and S6RP but had no inhibitory effect on phosphorylation of ERK1/2. Therefore, in LECs, PKCa is required for the activation of $\mathrm{PI} / \mathrm{K} / \mathrm{Akt} / \mathrm{mTOR}$ but is dispensable for the activation of ERK1/2, and SDC-4 KD inhibited ERK1/2 phosphorylation through mechanisms independent of PKCa. In addition, U1026, an ERK1/2 inhibitor, suppressed 
a
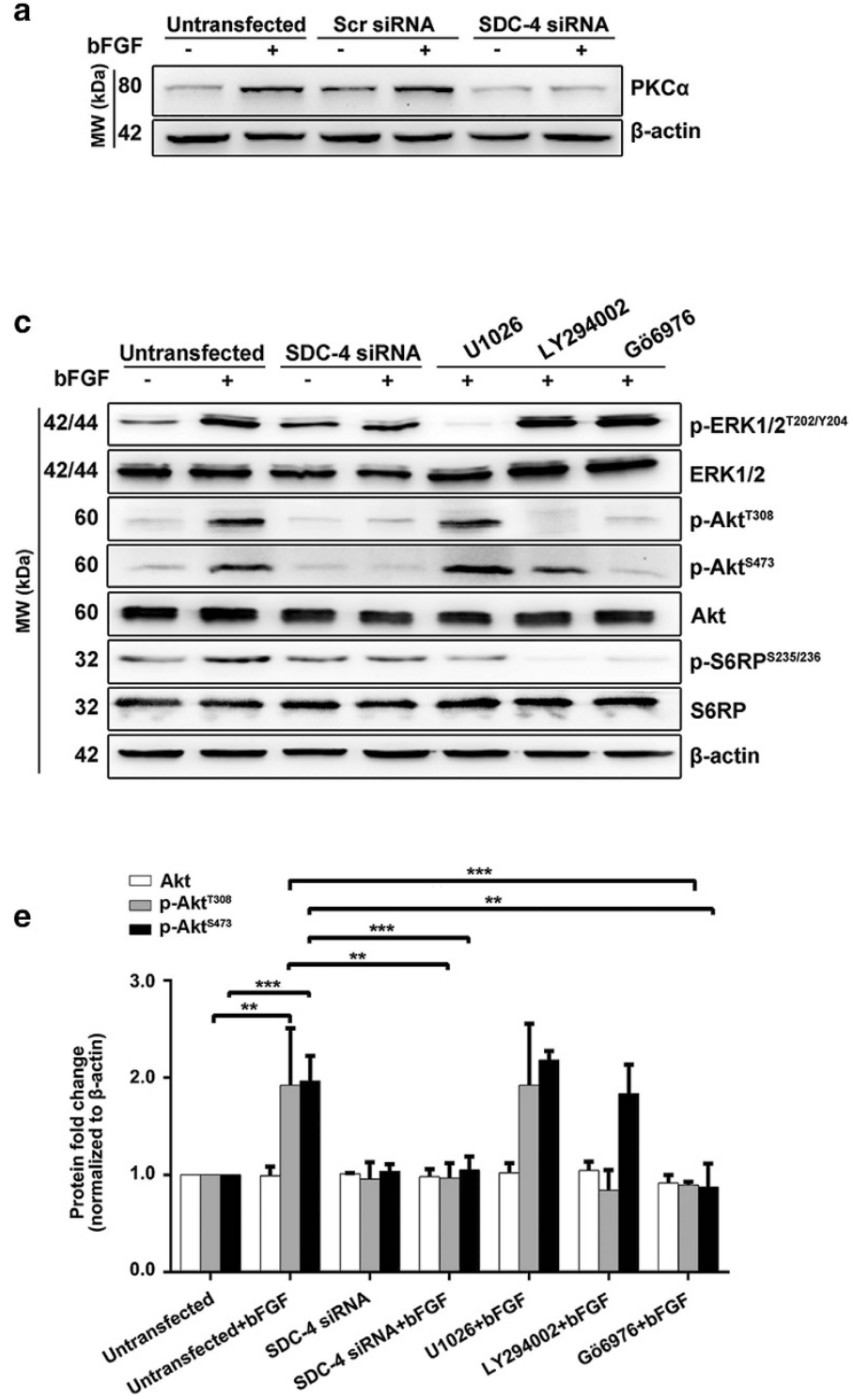

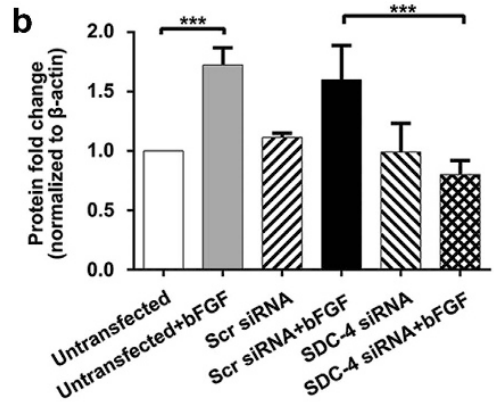

d

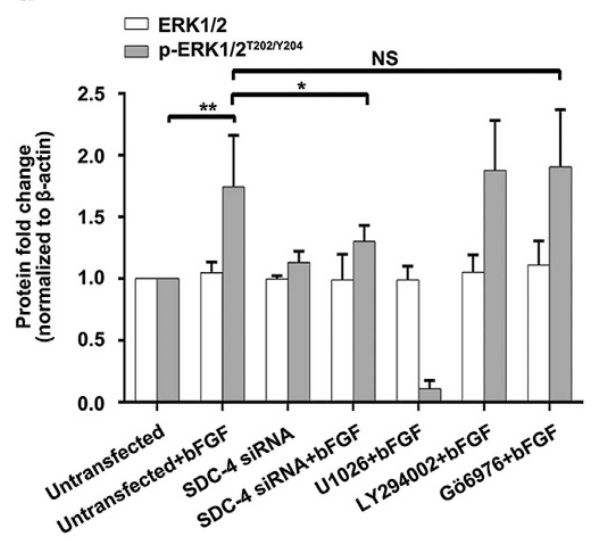

$\mathbf{f}$

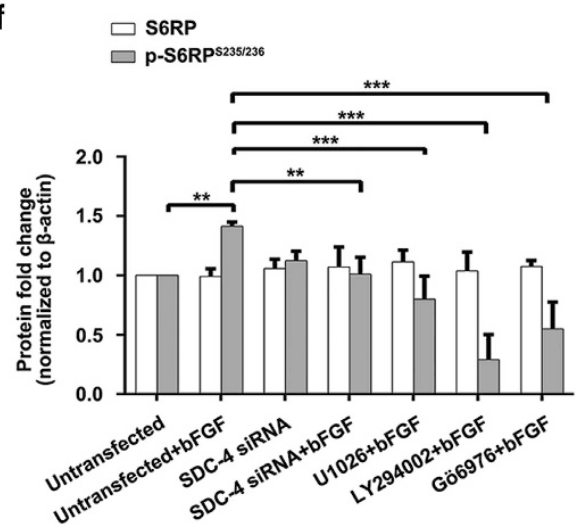

Figure 2 Downregulation of SDC-4 suppressed expression of PKC $\alpha$ and inhibited activation of the ERK1/2 and PI3K/Akt/mTOR pathways in LECs. (a) LECs were transfected with scrambled/SDC-4 siRNA and treated with/without $50 \mathrm{ng} / \mathrm{ml} \mathrm{bFGF}$ for $48 \mathrm{~h}$. Western blot analysis was performed to probe for PKC $\alpha(80 \mathrm{kDa})$. (b) Quantification of the protein expression levels in $\mathbf{a}$. The fold change relative to the level in the untransfected group is displayed. Data represent the mean \pm S.D. ${ }^{* \star *} P<0.001, n=3$. (c) LECs were transfected with SDC-4 siRNA and treated with/without $50 \mathrm{ng} / \mathrm{ml} \mathrm{bFGF} \mathrm{for} 48 \mathrm{~h}$, or LECs were pre-treated with U1026 (ERK1/2 inhibitor), LY294002 (PI3K inhibitor), or Gö6976 (PKC inhibitor) for $30 \mathrm{~min}$ and treated with $50 \mathrm{ng} / \mathrm{ml} \mathrm{bFGF}$ for $15 \mathrm{~min}$. Western blot analysis was performed to probe for p-ERK1/2 (42/44 kDa), total ERK (42/44 kDa), p-Akt $(60 \mathrm{kDa})$, total Akt $(60 \mathrm{kDa}), \mathrm{p}-\mathrm{S} 6 \mathrm{RP}(32 \mathrm{kDa})$, and total S6RP $(32 \mathrm{kDa})$. (d-f) Quantification of the protein expression levels in $\mathbf{c}$. The fold change relative to the level in the untransfected group is displayed. Data represent the mean \pm S.D. ${ }^{*} P<0.05,{ }^{* \star} P<0.01,{ }^{* \star \star} P<0.001$; NS, not significant, $n=3$

bFGF-induced S6RP phosphorylation, which is consistent with the previous finding that mTOR is a common downstream target of ERK1/2 and Akt. ${ }^{36}$

SDC-4 downregulation suppressed FGF-induced LEC migration. The migratory and proliferative effects of FGF have distinct pathways. FGF promotes cell migration through the activation of Src kinase and p38 mitogen-activated protein kinase (MAPK) rather than ERK or Akt. ${ }^{37}$ We next tested whether downregulation of SDC-4 also abrogated the migratory effects of FGF on LECs by the wound healing assay. ${ }^{26}$ We found that bFGF significantly increased LEC migration, which could be suppressed by SDC-4 KD (Figures $3 a$ and $b$ ). In addition, the transwell assay showed that SDC-4 KD significantly suppressed cell migration towards the FGF-containing medium (Figures $3 \mathrm{c}$ and d). Consistent with our findings, previous studies have shown that overexpression of SDC-4 increased the motility of 


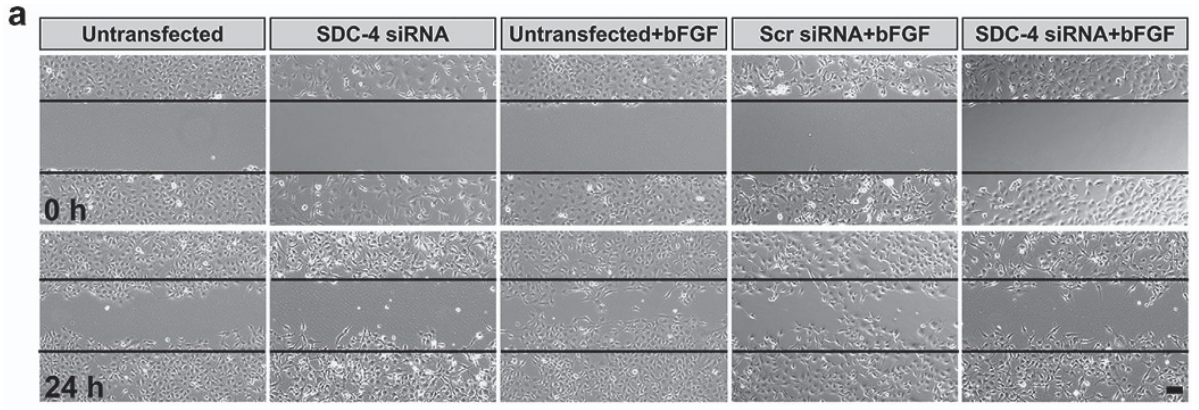

b

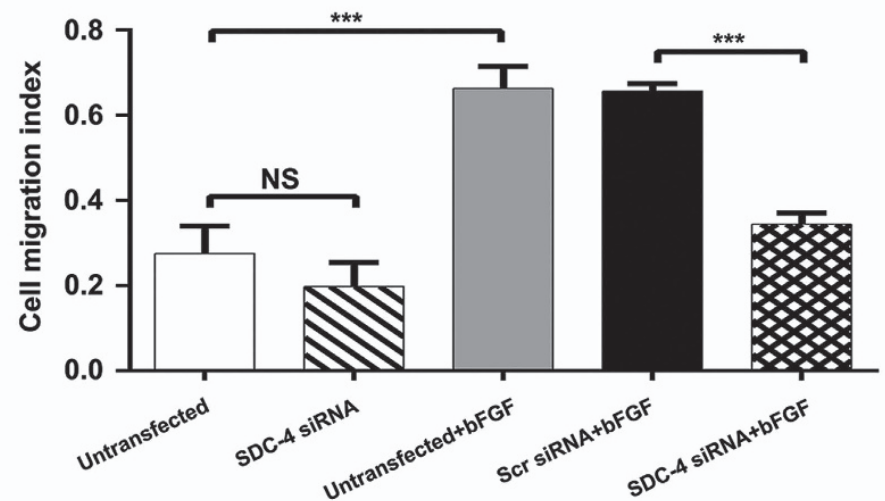

c
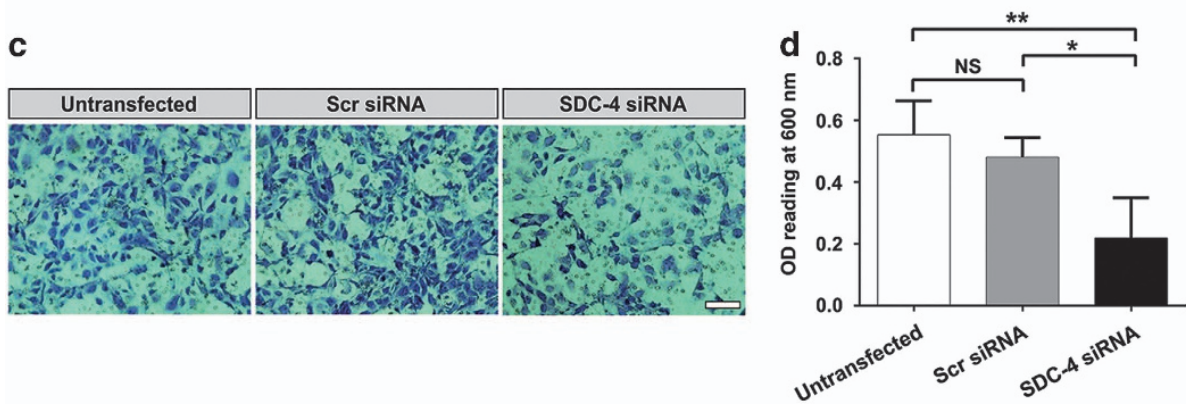

Figure 3 Downregulation of SDC-4 suppressed FGF-induced cell migration. (a) LECs were transfected with scrambled/SDC-4 siRNA and treated with/without $10 \mathrm{ng} / \mathrm{ml}$ bFGF for $24 \mathrm{~h}$. Cell migration was observed by using an inverted phase contrast microscope. Straight black lines indicate the wound edges. Scale bar, $100 \mu \mathrm{m}$. (b) Quantification of cell migration into the wound area. Data represent the mean \pm S.D. ${ }^{* \star *} P<0.001$, NS, not significant, $n=3$. (c) Representative images of LECs migrated to the lower chamber of the transwell filter. Scale bar, $100 \mu \mathrm{m}$. (d) Quantification of the migrated LECs. Cells stained with crystal violet were solubilized with acetic acid. The absorbance (OD $=600 \mathrm{~nm})$ was measured in a microplate reader. ${ }^{\star} P<0.05,{ }^{\star \star} P<0.01$; NS, not significant, $n=3$

keratinocytes and fibroblasts, ${ }^{38}$ and SDC-4 knockout (KO) in mice resulted in impaired wound repair and mesenchymal cell migration. ${ }^{39,40}$

\section{SDC-4 downregulation suppressed integrin-mediated} LEC adhesion. Integrin is presented on the surface of LECs and is an essential mediator of cell adhesion. ${ }^{41}$ Blockade of integrin signaling in LECs could effectively compromise LEC adhesion and prevent capsular opacification. ${ }^{42}$ As SDC-4 is also a co-receptor of integrin, we hypothesized that SDC-4 $\mathrm{KD}$ would block integrin-mediated cell adhesion. Indeed, we found reduced cell attachment to the ECM after SDC-4 KD (Figures $4 \mathrm{a}$ and $\mathrm{b}$, the OD values for the SDC-4 siRNA group and scrambled siRNA group were $0.253 \pm 0.022$ and $0.461 \pm 0.038$, respectively, $P<0.001)$. During cell adhesion, FAK is recruited to the cell-extracellular matrix interface and is essential for focal adhesion formation. ${ }^{14}$ We found that phosphorylation of FAK ( $p-\mathrm{FAK}^{\mathrm{Y} 397}$ ) was significantly increased in the presence of fibronectin and was suppressed upon SDC-4 KD, while the total FAK level was not affected, indicating that SDC-4 is required for FAK activation during focal adhesion formation (Figures $4 \mathrm{c}$ and d).

SDC-4 knockout suppressed injury-induced subcapsular cataract formation in an in vivo mouse model. Knowing that SDC-4 KD inhibited both FGF signaling and integrin signaling, we next examined whether SDC-4 inhibition could potentially prevent capsular opacification in vivo. First, we characterized the expression of SDC-4 in the eyes of 3-month-old wild-type (WT) mice, and found that SDC-4 was widely distributed in the lens epithelium, lens germinative zone, and retina (Figure 5a). The lenses from SDC- $4^{-1-}$ mice had significantly reduced expression level of SDC-4 (Figure $5 b$ ), but were still intact and transparent as those 

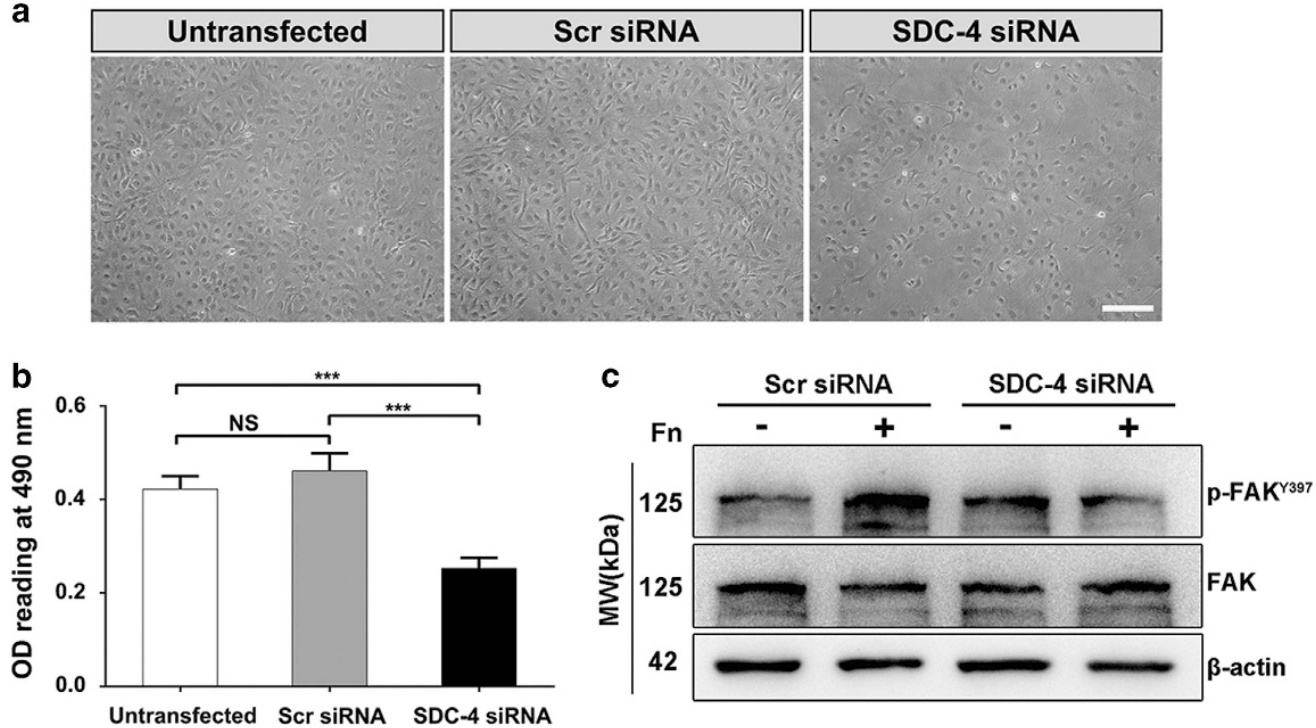

d

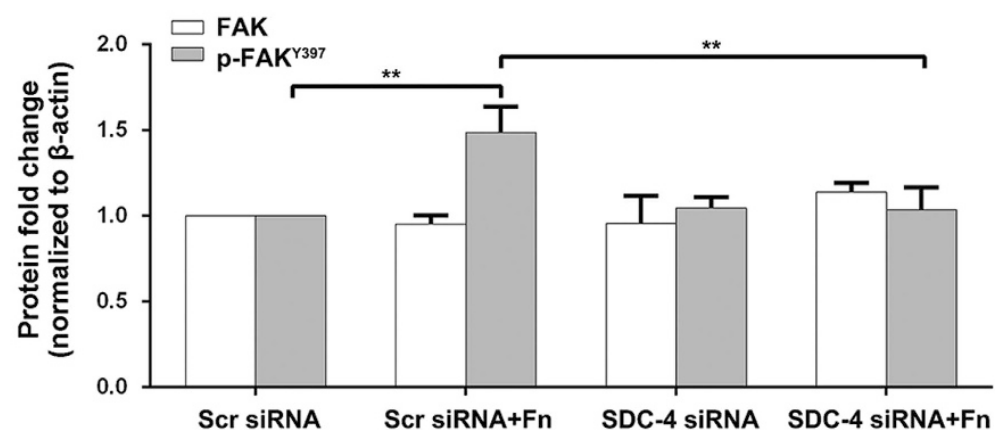

Figure 4 Downregulation of SDC-4 suppressed cell adhesion. (a) Representative inverted phase contrast microscope images of attached LECs transfected with scrambled/ SDC-4 siRNA. Scale bar, $100 \mu \mathrm{m}$. (b) Attached LECs were quantified by MTT assay. Data represent the mean \pm S.D. ${ }^{* \star *} P<0.001$; NS, not significant, $n=3$. (c) LECs were transfected with scrambled/SDC-4 siRNA and cultured on plates with/without precoating with fibronectin (Fn) for $6 \mathrm{~h}$. Western blot analysis was performed to probe for $p$-FAK $(125 \mathrm{kDa})$ and total FAK $(125 \mathrm{kDa})$. (d) Quantification of the protein expression levels in $\mathbf{c}$. The fold change relative to the level in the scrambled siRNA transfection group is displayed. Data represent the mean \pm S.D. ${ }^{\star *} P<0.01, n=3$

from WT mice (Figure 5c). Hematoxylin and eosin (H\&E) staining showed that lenses and retinas from SDC- $4^{-1-}$ mice were normal as those from WT mice (Figures $5 d$ and e). These results indicated that SDC-4 does not have a major role during the lens development. Consistently, a previous study showed that SDC-4 ${ }^{-/-}$mice had no macroscopic abnormalities and could reproduce normally. ${ }^{43}$

We have previously developed an injury-induced anterior subcapsular cataract (ASC) model in which the opacity can be quantitatively analyzed. ${ }^{44}$ Briefly, LEC proliferation was triggered by puncturing the anterior lens capsule with a hypodermic needle (Figure 6a). Although ASC and postoperative capsular opacification are regarded as two different types of cataracts, they share common molecular and cellular mechanisms, and both are regulated by the FGF and integrin signaling pathways. ${ }^{26,27,45-47}$ First, we analyzed the expression level of SDC-4 before and after injury by real-time PCR. We found that the expression level of SDC-4 was significantly upregulated at 1 day, 3 days, and 7 days after injury (Figure 6b), which is consistent with previous findings that SDC-4 is upregulated during wound healing. ${ }^{40,48}$ Next, we compared the development of ASC between wild-type (WT) mice and SDC-4-deficient (SDC-4 $4^{-1-}$ ) mice. We found that at 3 days after injury, WT mice developed obvious anterior capsule opacities. In contrast, SDC- $4^{-1-}$ mice only exhibited mild ASC even at day 7 after injury (Figure 6c, white arrows). Then, we used the laser scanning confocal microscopy threedimensional (LSCM-3D) imaging to quantify the opacity. We found that the volume of the subcapsular plaque in SDC- $4^{-/-}$ mice was significantly less than that in the WT mice at 3 days and 7 days after injury (Figure 6d). We also evaluated cell proliferation after injury through immunofluorescent staining of the injured anterior capsule whole-mount preparation by the proliferation marker Ki67. We found that SDC-4 $4^{-1-}$ mice showed less Ki67-positive cells, suggesting suppressed cell proliferation after injury (Figures $6 e$ and f). Consistent with our findings from the in vitro experiments, we found that the lens epithelium from SDC-4 ${ }^{-/-}$mice had reduced expression of PKC $a$ and less phosphorylation of ERK1/2, Akt, S6RP, and FAK after injury (Figures 7a-f). Moreover, the lens epithelium from SDC-4 ${ }^{-1}$ mice had significant higher expression level of E-cadherin, lower expression levels of $a$-SMA and vimentin, 
a
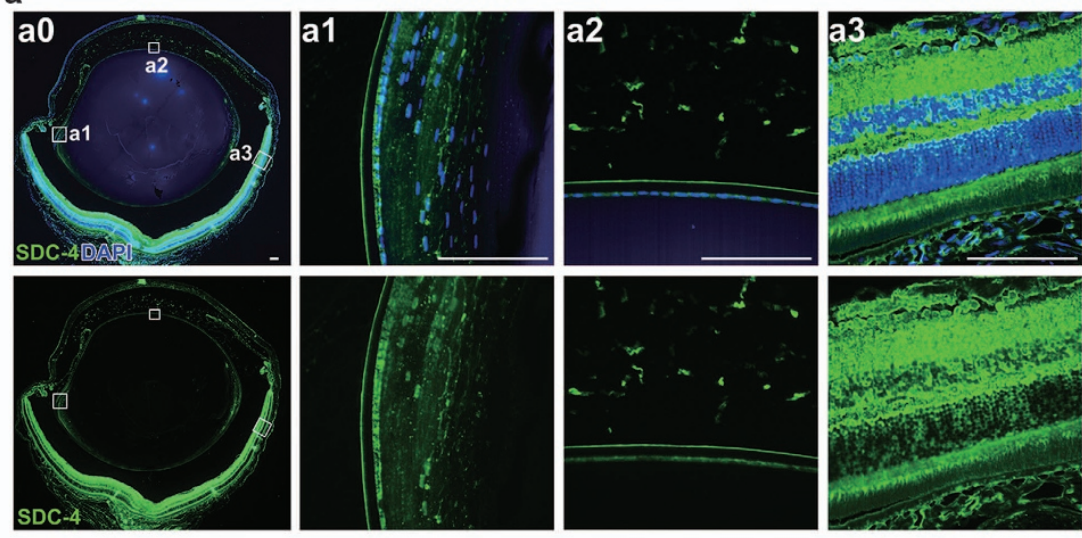

b

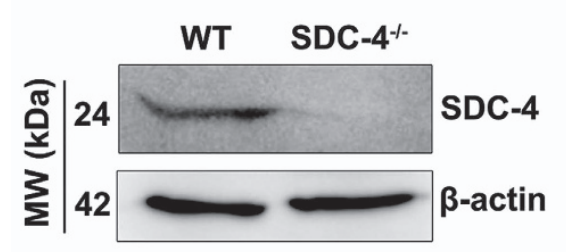

d

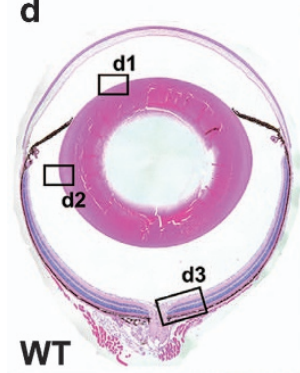

d1

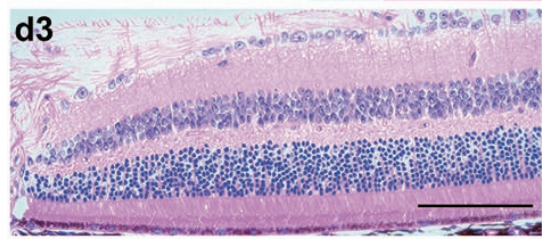

C

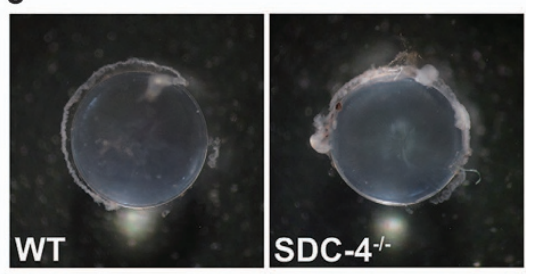

e

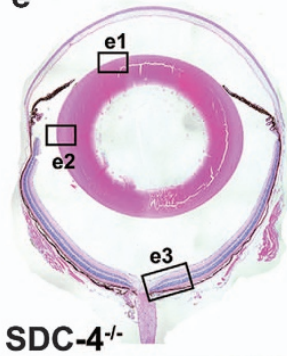

e1

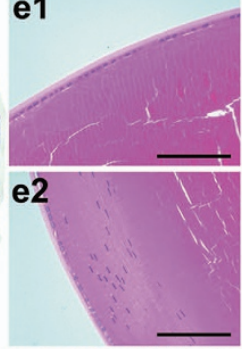

e3

Figure 5 SDC-4 knockout does not affect lens development in mice. (a) Paraffin sections from 3-month-old WT mice were probed for SDC-4 (green). DAPI (blue) was used to stain nuclei. SDC-4 was expressed in the anterior epithelium (a1), lens germinative zone (a2), and retina (a3). Scale bar, $100 \mu \mathrm{m}$. (b) Protein was extracted from the lenses from the 3-month-old WTand SDC-4 ${ }^{-1}$ - mice and probed for SDC-4. (c) Images of the lenses isolated from the 3-month-old WTand SDC- ${ }^{-1-}$ mice. (d and e) H\&E staining of eyes of the 3-month-old WT (d) and SDC-4 ${ }^{-1-}$ (e) mice. The lens anterior epithelium (d1 and e1), lens germinative zone (d2 and e2), and retina (d3 and e3) exhibited normal histology. Scale bar, $100 \mu \mathrm{m}$

and lower phosphorylation level of Smad2 at 3 and 7 days after injury, (Figures $7 \mathrm{~g}-\mathrm{i}$ ) indicating suppression of transforming growth factor (TGF)-induced epithelial to mesenchymal transition (EMT). Collectively, these in vivo findings demonstrated that SDC-4 KO could significantly suppress LEC proliferation and capsular opacification formation.

SDC-4 expression was increased in LECs derived from age-related cataract patients. Due to the essential role of SDC-4 during LECs proliferation, migration, and adhesion, understanding the regulation of SDC-4 in human LECs becomes key to unlocking its therapeutic potential. Although SDC-4 is widely expressed, the expression level of SDC-4 is usually low in normal tissue. ${ }^{49}$ Surprisingly, we found that SDC-4 mRNA expression in LECs from age-related cataract patients was approximately 7.853-fold higher than that from the human transparent lens (Supplementary Figure 6a). Consistently, immunofluorescent staining showed increased expression of SDC-4 in the LECs of the anterior capsule from age-related cataract patients (Supplementary Figure $6 \mathrm{~b}$ ). Consistent with our in vitro and in vivo results described above, findings from human patients further support the idea that deregulation of SDC-4 contributes to the development of postoperative capsular opacification, and downregulating SDC-4 may become a useful therapeutic strategy. 
a

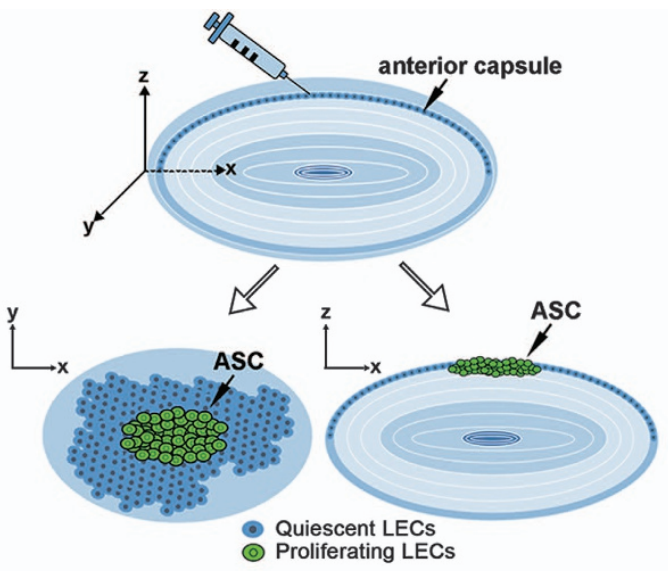

C

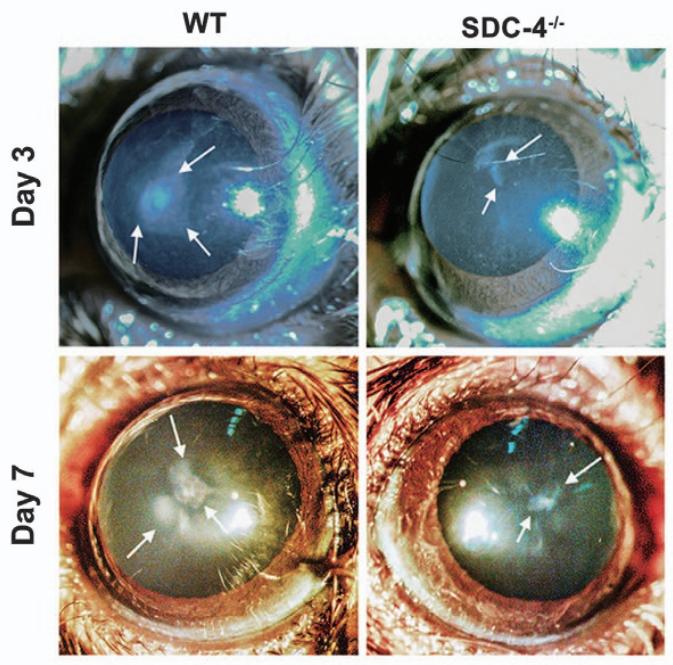

b

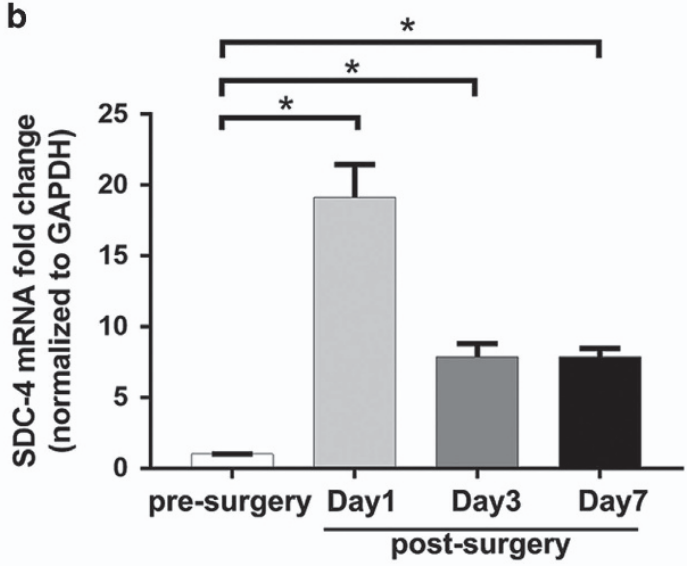

d

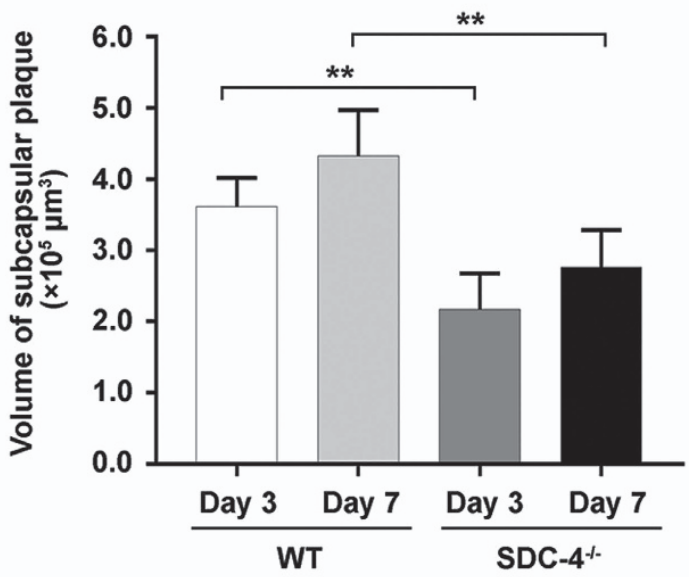

f

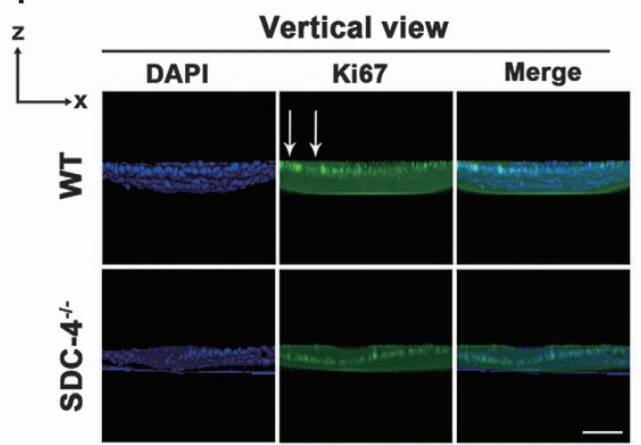

Figure 6 SDC-4 knockout suppressed injury-induced ASC formation in mice. (a) Cartoon schematic of the injury-induced ASC model. Puncture of the anterior capsule by a hypodermic needle initiates the proliferation of LECs around the injured area and finally leads to the development of ASC. (b) Total RNA was extracted from lenses of pre-surgery (control) or post-surgery of WT mice. The mRNA level of SDC-4 was determined using real-time PCR and normalized to GAPDH. Data represent the mean \pm S.D. ${ }^{*} P<0.05$, $n=3$. (c) Representative anterior segment slit-lamp microscope images of WTand SDC- $4^{-1}$ mice 3 days and 7 days after injury. White arrows indicate irregular fibrotic opacity (ASC). (d) Quantification of the anterior capsule opacity volume. Data represent the mean \pm S.D. ${ }^{*} P<0.01, n=3$. (e-f) Lens anterior capsule whole mounts from WT and SDC- $4^{-1-}$ mice were stained for Ki67 (green) and DAPI (blue). White arrows indicated Ki67-positive cells. Scale bar, $50 \mu \mathrm{m}$

\section{Discussion}

In this study, we, for the first time, characterized the role of SDC-4 in postoperative capsular opacification formation. In FGF signaling, SDC-4 engages the PKCa/Akt and ERK pathways to activate mTOR, inducing cell cycle progression.
In addition, SDC-4 is required for integrin-mediated cell adhesion through FAK phosphorylation (Figure 8). These results highlight the key regulatory role of SDC-4 in both FGF signaling and integrin signaling during the pathogenesis of capsular opacification. Moreover, SDC-4 inhibition suppressed FGF-induced cell cycle progression in RPE cells, 
a

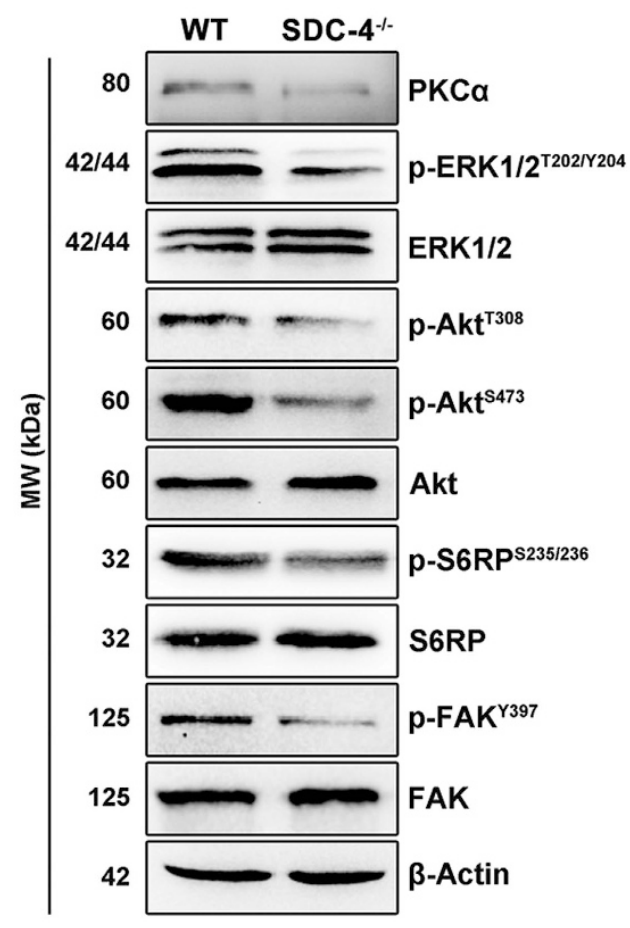

g

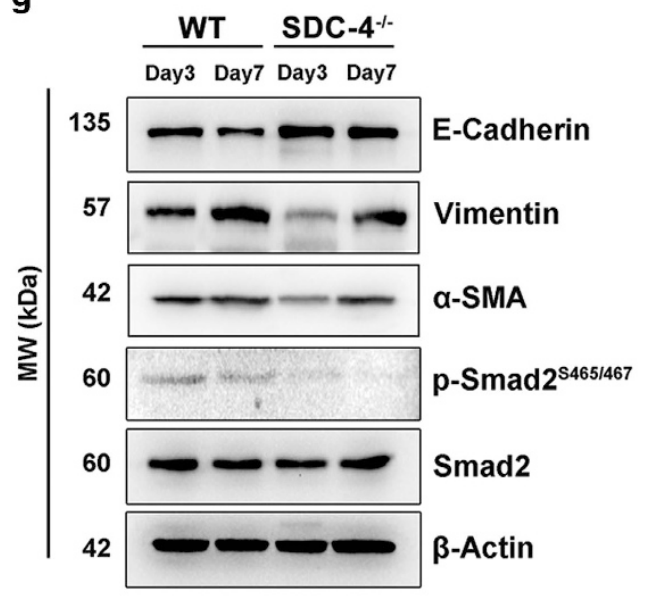

b
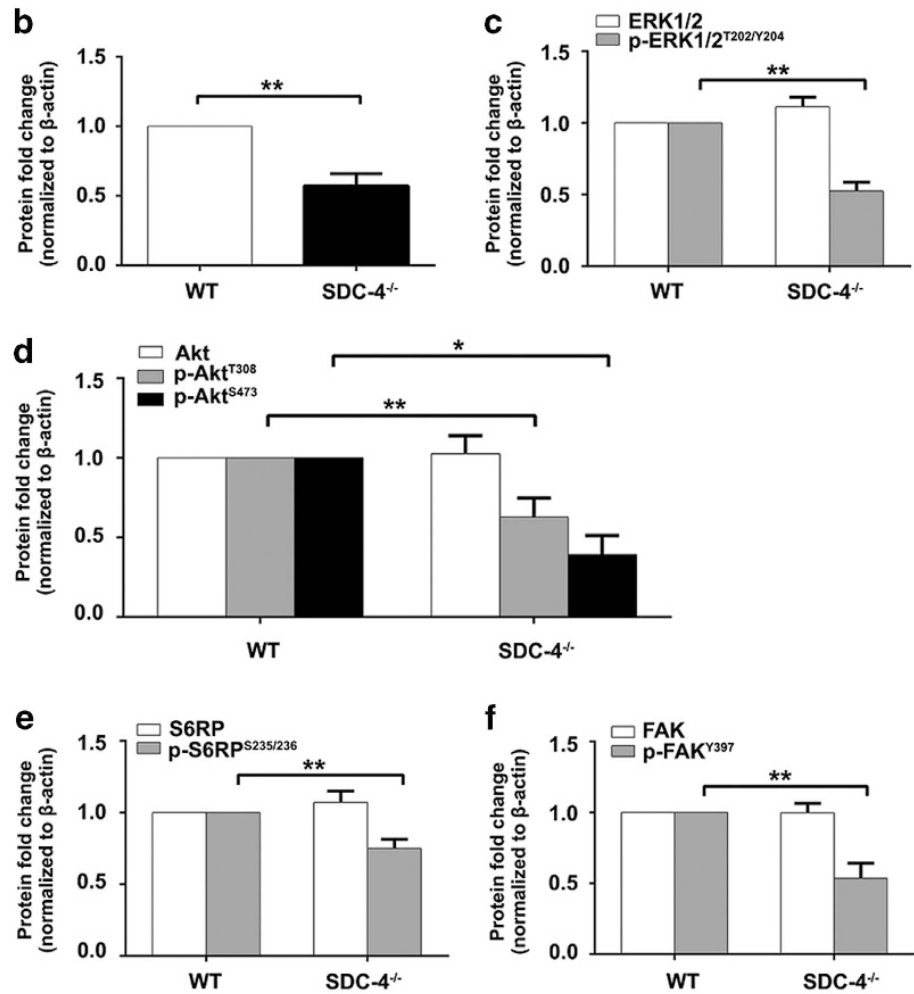

f

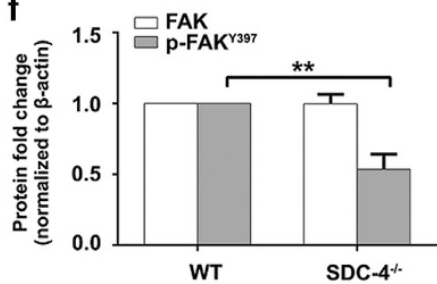

h $\quad$ WT Day3
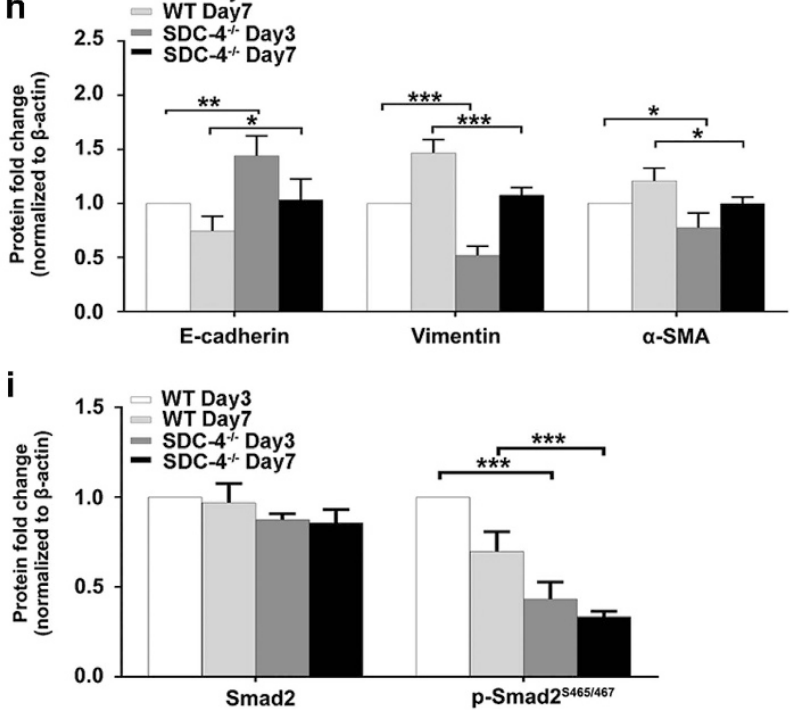

Figure 7 SDC-4 knockout suppressed expression of PKC $\alpha$, inhibited activation of the FAK, ERK1/2, PI3K/Akt/mTOR, and inhibited TGF-induced EMT in the injury-induced ASC mouse model. (a) Protein was extracted from the lens epithelium of WT and SDC- $-^{-1-}$ mice 3 days after injury and probed for PKC $\alpha$, p-ERK1/2, total ERK1/2, p-Akt, total Akt, $p$-S6RP, total S6RP, p-FAK, and total FAK. (b-f) Quantification of the protein expression levels in a. The fold change relative to the level in WT mice is displayed. Protein fold change was normalized to the WT mouse group. Data represent the mean \pm S.D. ${ }^{*} P<0.05,{ }^{*} P<0.01, n=3$. (g) Protein was extracted from the lens epithelium of WT and SDC- $4^{-1}$ mice 3 days and 7 days after injury, and probed for E-cadherin, vimentin, $\alpha$-SMA, p-Smad2, and total Smad2. (h-i) Quantification of the protein expression levels in $\mathrm{g}$. The fold change relative to the level in WT mice is displayed. Protein fold change was normalized to the WT mouse group at day 3 after injury. Data represent the mean \pm S.D. ${ }^{\star} P<0.05,{ }^{\star \star} P<0.01,{ }^{\star \star \star} P<0.001, n=3$

indicating that SDC-4 is also critical for the development other intraocular fibrotic disorders such as proliferative vitreoretinopathy (PVR), which is resulted from similar pathological processes including proliferation, migration, and EMT of the retinal pigment epithelium. ${ }^{50}$
SDC-4 is distinct from other SDC family members in that its cytoplasmic tail can bind $\mathrm{PIP}_{2}$ and activate PKCa. ${ }^{51,52}$ The binding of FGF to FGFR can activate a serine/threonine protein phosphatase type $1 / 2 \mathrm{~A}(\mathrm{PP} 1 / 2 \mathrm{~A})$, which will cause $\mathrm{Ser}^{183}$ dephosphorylation in the SDC-4 cytoplasmic tail. This 


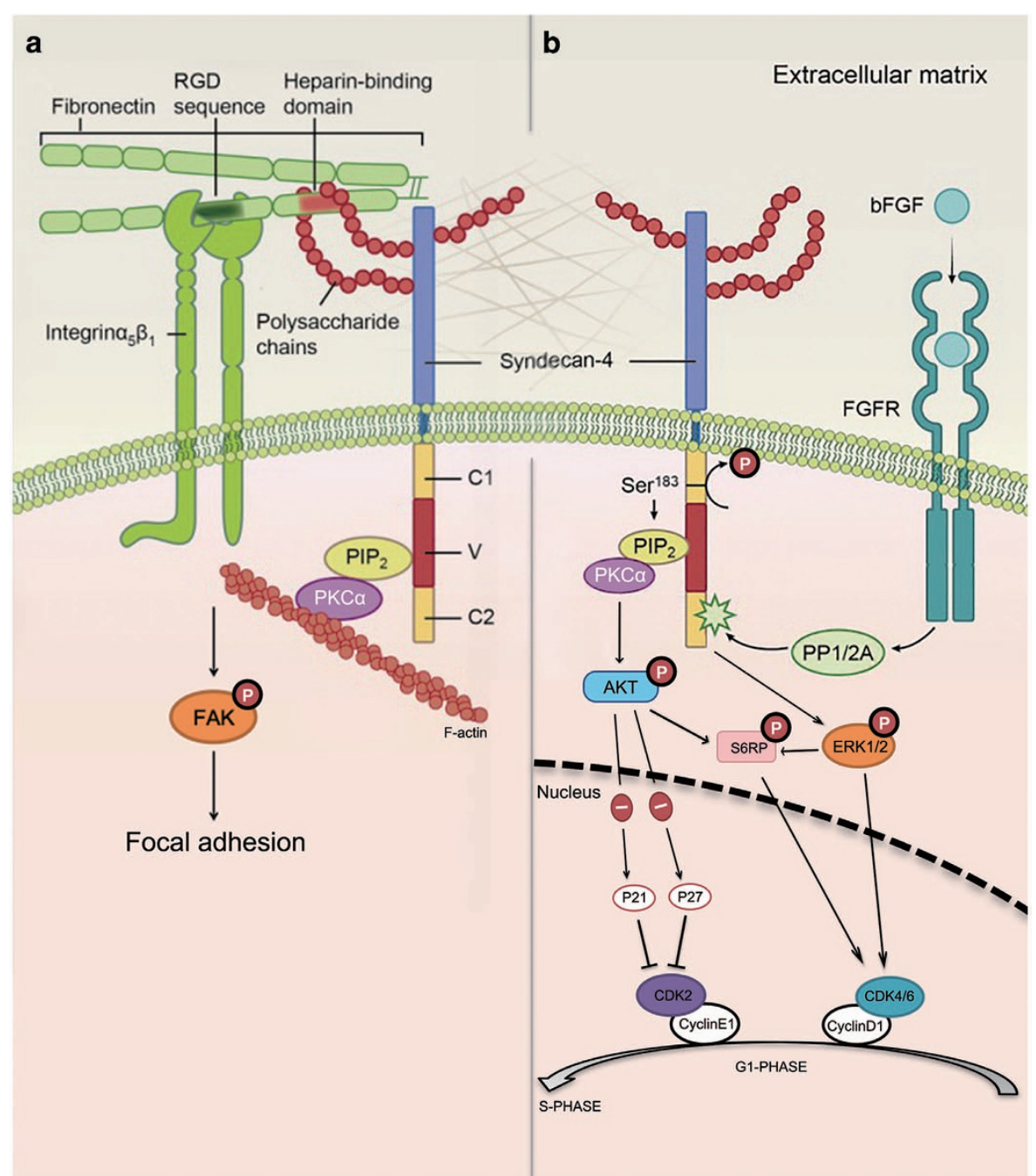

Figure 8 Schematic diagram of the role of SDC-4 in the regulation of the integrin and FGF signaling pathways. (a) SDC-4 functions as a co-receptor of integrin and mediates cell adhesion. ECM proteins, such as fibronectin, have an RGD sequence that binds to integrin and heparin-binding domains that bind to the polysaccharide side-chains of SDC-4, activating FAK and promoting focal adhesion formation. (b) SDC-4 also serves as a co-receptor of bFGF. The binding of FGF to FGFR activates PP1/2A, which leads to $\mathrm{Ser}^{183}$ dephosphorylation in the SDC-4 cytoplasmic tail. This dephosphorylation increases the binding affinity of PIP $\mathrm{P}_{2}$ to SDC-4 and activates PKC $\alpha$. PKC $\alpha$ further activates the $\mathrm{PI} I \mathrm{~K} / \mathrm{Akt} / \mathrm{mTOR}$ pathway. In addition, SDC-4 is required for the activation of ERK1/2, which also contributes to mTOR activation. Activation of PI3K/Akt/mTOR and ERK1/2 promotes the $\mathrm{G} 1 / \mathrm{S}$ transition

dephosphorylation increases the binding affinity of $\mathrm{PIP}_{2}$ to SDC-4 and activates PKC $a$ (Figure 8 ) ${ }^{20}$ Indeed, we show that downregulation of SDC-4 significantly suppressed FGFinduced $\mathrm{PKC} a$ upregulation in LECs. The downstream effectors of PKCa may include Akt and ERK, as previously reported. ${ }^{53}$ Our results showed that downregulation of SDC-4 or inhibition of PKCa suppressed $\mathrm{Akt}^{\mathrm{T} 308}$ and $\mathrm{Akt}^{\mathrm{S}}{ }^{\mathrm{T} 3}$ phosphorylation, indicating that Akt is a downstream target of SDC-4 and PKCa. Similarly, Akt ${ }^{\top 308}$ and $\mathrm{Akt}^{\mathrm{S} 473}$ phosphorylation is regulated by SDC-4 in a PKC $a$-dependent manner in endothelial cells. ${ }^{54,55}$ However, inhibition of PKCa did not affect $\mathrm{ERK}^{\mathrm{T} 202 / \mathrm{Y} 204}$ phosphorylation, but downregulation of SDC-4 did, suggesting that ERK ${ }^{\mathrm{T} 202 / \mathrm{N} 204}$ activation is independent of PKCa, but requires SDC-4 in FGF signaling. Consistent with our findings, FGF-induced ERK phosphorylation can be inhibited through SDC-4 downregulation in human umbilical vein endothelial cells. ${ }^{56}$ Notably, SDC-4 facilitates FGF signaling not only through Akt and ERK activation but also via FGF internalization and nuclear localization. ${ }^{38}$

SDC-4 is the only member of the SDC family that is presented in focal adhesion. ${ }^{57}$ The formation of focal adhesion requires two signals; one is the binding of integrin to the RGD sequence on fibronectin, and the other is the binding of SDC-4 to the heparin-binding domain. ${ }^{58}$ Therefore, SDC-4 serves as a bridge of the cytoskeletal proteins and the ECM. In this study, we found that SDC- 4 is essential for LEC adhesion to the ECM and that SDC-4 downregulation suppressed activation of FAK. This is consistent with a previous finding that SDC-4 modulates FAK tyrosine ${ }^{397}$ phosphorylation through a Rhodependent manner in fibroblast cells. ${ }^{59}$ As FAK activation also requires $\mathrm{PKC} a$, our finding strongly indicates that SDC-4 and $\mathrm{PKC} a$ are two key mediators that render cross-talk between 
FGF and integrin signaling. Indeed, FGF signaling closely interacts with integrin signaling. Rusnati et al. ${ }^{60}$ demonstrated that FGF interacts with $a \mathrm{~V} \beta 3$ integrin and that blocking $a \mathrm{~V} \beta 3$ integrin signaling diminishes FGF-induced adhesion and mitogenesis in endothelial cells. On the other hand, augmenting $\beta 1$-integrin activity can restore FGF sensitivity and promote cell proliferation. ${ }^{61}$

We found that SDC-4 level in LECs of cataract patients is significantly upregulated, which can subsequently promote cell proliferation and migration. Notably, this is not LEC-specific, but is common in cancer cells. The expression level of SDC-4 alters significantly during tumor progression and metastasis. For example, SDC-4 expression is upregulated in testicular germ cell tumor and osteosarcoma, and is correlated with the incidence of distant metastasis. ${ }^{62,63}$ SDC-4 overexpression is also highly associated with progression of breast cancer. ${ }^{64}$ Therefore, SDC-4 can be a potential biomarker and therapeutic target for cancer. Although specific SDC-4 inhibitor is currently unavailable, several previous studies demonstrated the efficacy of inhibitors of other SDC family members in cancer treatment. For example, nBT062, a SDC-1-specific monoclonal antibody, could inhibit the growth of multiple myeloma cells without inducing cytotoxicity against normal peripheral blood mononuclear cells. ${ }^{65}$ Also, OC-46F2, an antibody specifically targeting the extracellular domain of SDC-1, could inhibit tumor growth in human melanoma and ovarian carcinoma models. ${ }^{66}$ Moreover, an iodine-131-labeled anti-SDC-1 antibody is proved to be beneficial for refractory multiple myeloma patients in a phase I/II radioimmunotherapy study. ${ }^{67}$

The proliferation of the LECs and the differentiation of LECs into lens fibers are directly regulated by FGF signaling during lens development. ${ }^{68,69}$ Low level of FGF was found to induce LECs proliferation, whereas higher level of FGF could promote cell cycle exit and differentiate into anuclear lens fibers. ${ }^{70}$ During the development of ACO and PCO, the differentiation of LECs into mesenchymal cells (EMT) is different from the differentiation of LECs into anuclear lens fibers. Tanaka et al. ${ }^{71}$ have demonstrated that during the wound healing response in lens, endogenous FGF is required for cell proliferation but not essential for EMT. Instead, TGF is the key regulator that induce LECs to undergo EMT after cataract surgery. ${ }^{44,72,73,74,75}$ Recently, growing evidence suggests that SDC family also participates in TGF signaling. For example, in lung adenocarcinoma A549 cells, TGF- $\beta_{1}$ induces upregulation of SDC-4, leading to enhanced cell proliferation, migration, and EMT. ${ }^{76}$ Conversely, the SDC-4 KO mouse exhibited a significant reduction in aristolochic acid nephropathy-induced recruitment of TGF- $\beta_{1}$ in the kidney and less fibrosis. ${ }^{77} \mathrm{We}$ found that after injury, compared with WT mice, SDC-4 KO mice exhibited higher expression level of epithelial marker, lower expression levels of mesenchymal markers, and reduced phosphorylation of Smad2, suggesting that SDC-4 also contributes to TGF-induced EMT of LECs. The role of SDC-4 in signaling pathways of other growth factors is still open to answer in this field.

Taken together, our data from in vitro human LECs, in vivo mouse ASC model, as well as human cataract patients consistently support the idea that targeting SDC-4 can effectively suppress bFGF-induced proliferation and migration, as well as integrin-mediated adhesion of LECs. Although further translational studies are needed, our findings provide both molecular mechanisms and clinical associations as a basis for developing interventional strategies against postoperative capsular opacification through targeting SDC-4.

\section{Materials and Methods}

Cell culture and treatment. The immortalized human lens epithelial cell line SRA 01/04, HLE-B3 and human retinal pigment epithelial cell line ARPE-19 were kindly provided by Professor Fu Shang at Laboratory Nutrition and Vision Research (Boston, MA, USA) and cultured in Dulbecco's Modified Eagle Medium (DMEM; GIBCO, Grand Island, NY, USA) supplemented with $10 \%$ fetal bovine serum (FBS; GIBCO, Grand Island, NY, USA) in a humidified $37{ }^{\circ} \mathrm{C}$ incubator with a $5 \% \mathrm{CO}_{2}$ atmosphere. For siRNA transfection, the cells were plated in a six-well culture plate until they reached $70 \%$ confluence and were then transfected with SDC-4 siRNA (sc-36588, Santa Cruz Biotechnology, CA, USA) or scrambled siRNA (sc-37007, Santa Cruz Biotechnology) according to the manufacturer's protocol. An optimal siRNA concentration of $60 \mathrm{nM}$ was determined through FITC-labeled siRNA (sc36869, Santa Cruz Biotechnology) transfection followed by flow cytometry (BD Biosciences, San Jose, CA, USA).

Cell proliferation assay. The cells were cultured in a 96-well plate at a density of $1 \times 10^{4}$ cells/well with serum-free medium for $24 \mathrm{~h}$, transfected with siRNA, and treated with $50 \mathrm{ng} / \mathrm{ml}$ bFGF (Peprotech, Rocky Hill, NJ, USA) for $48 \mathrm{~h}$. For cell counting kit-8 (CCK-8) assay, $10 \mu$ of CCK-8 solution (Dojindo, GMBH, EU) was added to each well and incubated at $37^{\circ} \mathrm{C}$ for $2 \mathrm{~h}$. The absorbance values were detected at a wavelength of $450 \mathrm{~nm}$ by a 96-well multiscanner autoreader (Synergy H1, BioTek, Winooski, VT, USA). Wells with only culture medium were used as a blank control. Inhibition rate $=\left(\mathrm{OD}_{\mathrm{Scr} \text { siRNA group }}-\mathrm{OD}_{\mathrm{SDC}-4 \text { siRNA group }}\right) /$ $O D_{\text {Scr siRNA group }} \times 100 \%$. Data were obtained from three independent experiments with five replicates for each group in each experiment.

Cell cycle analysis. The cells were treated with serum-free medium for $24 \mathrm{~h}$ and then treated with $50 \mathrm{ng} / \mathrm{ml} \mathrm{bFGF}$ for $48 \mathrm{~h}$. Then, the cells were collected and fixed in $70 \%$ ethanol overnight at $4{ }^{\circ} \mathrm{C}$. After that, the cells were centrifuged and suspended in $0.2 \mathrm{ml}$ propidium iodide for $30 \mathrm{~min}$. The cell cycle was analyzed by flow cytometry (BD Biosciences) with a 540-nm laser.

Scratch wound assay. The cells were plated in a six-well culture plate and cultured until they reached $90 \%$ confluence. The cell monolayer was wounded by a 200- $\mu$ l micropipette tip and washed with phosphate-buffered saline (PBS) three times to remove cell debris. After that, the cells were cultured in FBS-free DMEM with or without $10 \mathrm{ng} / \mathrm{ml} \mathrm{bFGF}$ for $24 \mathrm{~h}$. The wound area was photographed using an inverted microscope. Image-Pro Plus 6.0 (Media Cybernetics Inc., Silver Spring, $M D$, USA) was used to analyze the migration distance. Cell migration index $=(1-$ noninvading area/total wounded area $) \times 100 \%$.

Transwell migration assay. A transwell migration assay was performed using a 24-well filter plate with an 8.0- $\mu \mathrm{m}$ pore size (Corning Incorporated, Corning, NY, USA). LECs in $100 \mu \mathrm{l}$ FBS-free DMEM were seeded in the upper chamber at a density of $1 \times 10^{5}$ cells/well, and $500 \mu \mathrm{l}$ DMEM containing FGF was added to the lower chamber. After a $24 \mathrm{~h}$ incubation, the remaining cells in the upper side of the filter were scraped with a cotton swab, and the penetrating cells in the lower layer were fixed in methanol and stained in crystal violet. Three randomly chosen fields were photographed by using an inverted microscope. The stained cells were solubilized with $200 \mu \mathrm{l} 10 \%$ acetic acid, and the absorbance was measured at 600 $\mathrm{nm}$ by a 96 -well multiscanner autoreader.

Cell adhesion assay. The cells treated with siRNA for $48 \mathrm{~h}$ were trypsinized, resuspended, and added to a 96-well plate precoated with fibronectin (sc-29011, Santa Cruz Biotechnology) at a density of $1 \times 10^{4}$ cells/well. After incubation at $37^{\circ} \mathrm{C}$ for $3 \mathrm{~h}$, the cells were washed gently with PBS three times. Cell adhesion was photographed by using an inverted microscope. Then, $10 \mu \mathrm{l}$ of $5 \mathrm{mg} / \mathrm{ml}$ MTT was added to each well and incubated at $37^{\circ} \mathrm{C}$ in a $\mathrm{CO}_{2}$ incubator for $4 \mathrm{~h}$. The formazan granules were dissolved in $150 \mu \mathrm{l}$ DMSO, and the absorbance values were detected at a wavelength of $490 \mathrm{~nm}$ by a $96-$ well multiscanner autoreader. 
Mouse lens capsular injury model. SDC-4 knockout (KO) mice were kindly provided by Professor Rong Ju at Zhongshan Ophthalmic Center (Guangzhou, Guangdong, China). ${ }^{78,79}$ Six- to eight-week-old SDC-4 ${ }^{-/-}$and age-matched WT mice were used in the study. All animal experiments were conducted in accordance with the approved guidelines of the Ethics Committee in Animal Experimentation of Zhongshan Ophthalmic Center (No. 2016-015). Mouse lens capsular injury was performed as described previously. ${ }^{44}$ Briefly, the mice were anesthetized with $0.2 \mathrm{ml} 5 \%$ Cholrali Hydras and dicaine eyedrop. After topical application of mydriatic, a 26-gauge hypodermic needle was used to make an incision in the central anterior capsule of the right eye through the cornea. The depth of the incision was one-fourth the length of the blade $(\sim 300 \mu \mathrm{m})$. The mice were photographed by using a slit lamp 3 days after injury.

Collection of human anterior capsule samples. The anterior capsule samples were obtained from aged-related cataract patients during cataract surgeries. All the surgeries were conducted by one surgeon (Mingxing Wu), and each capsule was about $5 \mathrm{~mm}$ in diameter. Informed consent was obtained from the patients before surgery. Age-matched anterior capsule samples from transparent lens were obtained from cadaver eye in the eye bank of Zhongshan Ophthalmic Center. The research conformed to the tenets of the Declaration of Helsinki and followed the protocol approved by the Institutional Research Board of Zhongshan Ophthalmic Center. Lens anterior capsule whole mounts were prepared as previously described. ${ }^{26}$

Immunofluorescence. For immunofluorescent staining of the whole-mount lens anterior capsules in the capsular injury model, the mice were killed, and the eyes were enucleated 3 days after injury. The anterior capsules were isolated under a dissecting microscope. The capsules were immediately fixed in 100\% methano for $1 \mathrm{~h}$ at room temperature (RT), permeated with $0.1 \%$ Triton $\mathrm{X}-100$ for $30 \mathrm{~min}$, and blocked with $1 \%$ bovine serum albumin (BSA) for $60 \mathrm{~min}$. Then, the capsules were incubated with the anti-Ki67 antibody (1:250; Abcam, Cambridge, MA, USA) diluted in $1 \% \mathrm{BSA}$ at $4{ }^{\circ} \mathrm{C}$ overnight, briefly washed with PBS containing $0.1 \%$ Tween 20 (PBST), and incubated with the FITC-conjugated antibody (1:500; Cell Signaling Technology, Danvers, MA, USA) at RT for $60 \mathrm{~min}$. The nuclei of the cells were stained with DAPI for $5 \mathrm{~min}$. The capsule was placed flat on a microscope slide under a dissecting microscope and covered with a coverslip. Images were observed by using a Zeiss LSM 510 confocal microscope. Two-dimensional (2D) images were taken at $2 \mu \mathrm{m}$ intervals to generate $z$-stacks and then converted into three-dimensional (3D) images. The volume of the anterior capsule opacities between two images was calculated using the formula of a frustum $V=1 / 3 \times H \times\left[S_{\text {upper base }}+S_{\text {lower base }}+\sqrt{S_{\text {upper base }} \times S_{\text {lower base }}}\right]$. The basal area was measured by using Image-Pro Plus 6.0 (Media Cybernetics Inc.). The total volume of the anterior capsule plaque was calculated as $V_{\text {total }}=V_{1}+V_{2}+\ldots+V_{n}$.

For immunofluorescent staining of the paraffin section, eyes were enucleated from killed 3-month-old mice, fixed with $4 \%$ paraformaldehyde for $24 \mathrm{~h}$, dehydrated in ethanol, and embedded in paraffin. Paraffin sections with $4 \mu \mathrm{m}$ thickness were incubated at $60^{\circ} \mathrm{C}$ for $30 \mathrm{~min}$ and dewaxed using xylenes. After dehydrated in ethanol and antigen retrieval, sections were subject to immunohistochemical staining. Images were taken by Zeiss LSM 510 confocal microscope.

For immunofluorescent staining of the cultured LECs/anterior capsule whole mounts, the samples were fixed with $4 \%$ paraformaldehyde, permeabilized with $0.1 \%$ Triton X-100, blocked with $1 \%$ bovine serum albumin (BSA) for $60 \mathrm{~min}$. After that, the samples were incubated with the anti-SDC-4 antibody (1:100; Abcam) at $4^{\circ} \mathrm{C}$ overnight and FITC-conjugated antibody (1:500; Cell Signaling Technology) at RT for $60 \mathrm{~min}$. The nuclei of the LECs were stained with DAPI for 5 min. Images were taken by using a Zeiss LSM 510 confocal microscope.

H\&E staining. The 3-month-old WT mice and SDC-4 $4^{-1-}$ mice were killed. The eyes were enucleated and fixed with $4 \%$ paraformaldehyde for $24 \mathrm{~h}$ at room temperature. The paraffin sections were sectioned from the optic nerve at $4 \mu \mathrm{m}$ thickness, and stained with H\&E. Images were taken by a Leica DM4000 B upright microscope.

Western blot analysis. The cells or lens tissue were lysed in RIPA buffer supplied with protease and phosphatase inhibitor cocktail. The protein concentration was determined using the BCA-100 Protein Quantitative Analysis Kit (Biocolor Bioscience \& Technology Co., Ltd., Shanghai, China). Equal amounts of protein (15 $\mu \mathrm{g} /$ lane) were resolved in $10 \%$ sodium dodecyl sulfate-polyacrylamide gel electrophoresis (SDS-PAGE). The proteins were then transferred to polyvinylidene fluoride membranes (PVDF membranes; Millipore, MA, USA) for probing with primary antibodies and horseradish peroxidase (HRP)-conjugated secondary antibodies. Signals were detected with an eECL Western Blot Kit (ComWin Biotech Co., Ltd, Beijing, China). $\beta$-actin was used as a reference. The sources of the antibodies used are as follows: rabbit anti-SDC-4 (1:1000; Abcam), mouse anticyclin E1 (1:1000; Cell Signaling Technology), mouse anti-cyclin D1 (1:2000; Cell Signaling Technology), mouse anti-CDK6 (1:1000; Cell Signaling Technology), mouse anti-CDK4 (1:1000; Cell Signaling Technology), rabbit anti-CDK2 (1:1000; Cell Signaling Technology), rabbit anti-P27 (1:1000; Cell Signaling Technology), rabbit anti-P21 (1:2000; Cell Signaling Technology), mouse anti-PCNA (1:1000; Novus Biologicals, Littleton, CO, USA), rabbit anti-caspase-3 (1:1000; Abcam), rabbit anti-caspase-9 (1:1000; Abcam), rabbit anti-PKC $\alpha$ (1:1000; Cell Signaling Technology), rabbit anti-p-Akt (1:500; T308, Cell Signaling Technology), mouse antip-Akt 1:500; S473, Cell Signaling Technology), rabbit anti-Akt (1:1000; Cell Signaling Technology), rabbit anti-p-ERK1/2 (1:1000; T202/Y204, Cell Signaling Technology), rabbit anti-ERK1/2 (1:1000; Cell Signaling Technology), rabbit anti-pS6RP (1:2000; S235/236, Cell Signaling Technology), rabbit anti-S6RP (1:1000; Cell Signaling Technology), rabbit anti-p-FAK (1:500; Y397, Cell Signaling Technology), rabbit anti-FAK (1:1000; Cell Signaling Technology), rabbit anti-E-cadherin (1:1000; Cell Signaling Technology), mouse anti-vimentin (1:1000; Abcam), mouse anti- $\alpha$ SMA (1:1000; Abcam), rabbit anti-p-Smad2 (1:1000; S465/467, Cell Signaling Technology), rabbit anti-Smad2 (1:1000; Cell Signaling Technology) and mouse anti$\beta$-actin (1:2000; Cell Signaling Technology). The signal density was quantified by using ImageJ 1.48 (National Institutes of Health, Bethesda, MD, USA).

Total RNA extraction and real-time PCR. Total RNA was isolated from tissue samples and LECs using RNEasy Micro kit (Qiagen, Hilden, Germany) and high pure RNA tissue kit (Roche, Mannheim, Germany), respectively. A Transcriptor First Strand cDNA synthesis kit (Roche) was used for reverse transcription. The LightCycler 480 SYBR Green I Master (Roche) was used to amplify the target genes, which were detected by using a LightCycler480II real-time PCR system (Roche). $\beta$-actin and GAPDH were used as an internal control. Primer sequences were as follows: human SDC-4 (F), 5'-CTCCTAGAAGGCCGATACTTCT-3'; human SDC-4 (R), 5'-GGACCTCCGTTCTCTCAAAGAT-3'; human $\beta$-actin (F), $5^{\prime}$-GGACT TCGAGCAAGAGATGG-3'; human $\beta$-actin (R), $5^{\prime}$-AGCACTGTGTTGGCGTAC AG-3'; mouse SDC-4 (F), 5'-ATGTCCAACAAAGTATCCATGTCCA-3'; mouse SDC-4 (R), 5'-ATGCGGTACACCAGCAGCAG-3'; mouse GAPDH (F), 5'-GCCA AGGCTGTGGGCAAGGT-3'; mouse GAPDH (R), 5'-TCTCCAGGCGGCACG TCAGA-3'.

Statistical analysis. Statistical analysis was performed with a statistical software package (SPSS, version 16.0, Chicago, IL, USA). The data of each group were compared and expressed as the mean \pm S.D. Statistical significance was determined by independent sample $t$-test between two groups or by one-way analysis of variance (ANOVA) followed by post hoc Fisher's least significant difference (LSD) test between multiple groups. All tests were two-tailed. Values of $P<0.05$ were considered statistically significant.

\section{Conflict of Interest}

The authors declare no conflict of interest.

Acknowledgements. We thank Professor Fu Shang and Professor Rong Ju for kindly providing the cell lines and SDC- $4^{-1-}$ mice, respectively. This study was supported by grant 81270982 from National Natural Science Foundation of China and grant 2014A030313082 from National Natural Science Foundation of Guangdong, China.

1. Tan $X$, Lin H, Li Y, Huang L, Zhu Y, Ni Y et al. Cataract screening in a rural area of Southern China: a retrospective cohort study. Lancet 2016; 388(Suppl 1): S53.

2. Khairallah M, Kahloun R, Bourne R, Limburg H, Flaxman SR, Jonas JB et al. Number of people blind or visually impaired by cataract worldwide and in world regions, 1990 to 2010 . Invest Ophthalmol Vis Sci 2015; 56: 6762-6769.

3. Apple DJ, Mamalis N, Loftfield K, Googe JM, Novak LC, Kavka-Van Norman D et al. Complications of intraocular lenses. A historical and histopathological review. Surv Ophthalmol 1984; 29 : 1-54. 
4. Xi L, Liu Y, Zhao F, Chen C, Cheng B. Analysis of glistenings in hydrophobic acrylic intraocular lenses on visual performance. Int J Ophthalmol 2014; 7: 446-451.

5. Macky TA, Pandey SK, Werner L, Trivedi RH, Izak AM, Apple DJ. Anterior capsule opacification. Int Ophthalmol Clin 2001; 41: 17-31.

6. Awasthi N, Guo S, Wagner B. Posterior capsular opacification: a problem reduced but not yet eradicated. Arch Ophthalmol 2009; 127: 555-562

7. Kruger AJ, Amon M, Schauersberger J, Abela-Formanek C, Schild G, Kolodjaschna J. Anterior capsule opacification and lens epithelial outgrowth on the intraocular lens surface after curettage. J Cataract Refract Surg 2001; 27: 1987-1991.

8. Abela-Formanek C, Amon M, Schild G, Schauersberger J, Heinze G, Kruger A. Uveal and capsular biocompatibility of hydrophilic acrylic, hydrophobic acrylic, and silicone intraocular lenses. J Cataract Refract Surg 2002; 28: 50-61.

9. Huang XD, Yao K, Zhang Z, Zhang Y, Wang Y. Uveal and capsular biocompatibility of an intraocular lens with a hydrophilic anterior surface and a hydrophobic posterior surface. $J$ Cataract Refract Surg 2010; 36: 290-298.

10. Tan X, Zhan J, Zhu Y, Cao J, Wang L, Liu S et al. Improvement of uveal and capsular biocompatibility of hydrophobic acrylic intraocular lens by surface grafting with 2methacryloyloxyethyl phosphorylcholine-methacrylic acid copolymer. Sci Rep 2017; 7: 40462 .

11. Auffarth GU, Golescu A, Becker KA, Völcker HE. Quantification of posterior capsule opacification with round and sharp edge intraocular lenses. Ophthalmology 2003; 110: 772-780.

12. Katayama $Y$, Kobayakawa S, Yanagawa $H$, Tochikubo $T$. The relationship between the adhesion characteristics of acrylic intraocular lens materials and posterior capsule opacification. Ophthalmic Res 2007; 39: 276-281.

13. Huang YS, Bertrand V, Bozukova D, Pagnoulle C, Labrugere C, De Pauw E et al. RGD surface functionalization of the hydrophilic acrylic intraocular lens material to control posterior capsular opacification. PLOS ONE 2014; 9: e114973.

14. Wederell ED, de longh RU. Extracellular matrix and integrin signaling in lens development and cataract. Semin Cell Dev Biol 2006; 17: 759-776.

15. Sinha R, Shekhar H, Sharma N, Titiyal JS, Vajpayee RB. Posterior capsular opacification: a review. Indian J Ophthalmol 2013; 61: 371.

16. Beenken A, Mohammadi M. The FGF family: biology, pathophysiology and therapy. Nat Rev Drug Discov 2009; 8: 235-253

17. lyengar L, Patkunanathan B, McAvoy JW, Lovicu FJ. Growth factors involved in aqueous humour-induced lens cell proliferation. Growth Factors 2009; 27: 50-62.

18. Lin Y, Liang X, Ai S, Chen C, Liu X, Luo L et al. FGFR2 molecular analysis and related clinical findings in one Chinese family with Crouzon syndrome. Mol Vis 2012; 18: 449-454.

19. Lin Y, Ai S, Chen C, Liu X, Luo L, Ye S et al. Ala344Pro mutation in the FGFR2 gene and related clinical findings in one Chinese family with Crouzon syndrome. Mol Vis 2012; 18: 1278-1282.

20. Elfenbein A, Simons M. Syndecan-4 signaling at a glance. J Cell Sci 2013; 126: 3799-3804

21. Afratis NA, Nikitovic D, Multhaupt HA, Theocharis AD, Couchman JR, Karamanos NK Syndecans: key regulators of cell signaling and biological functions. FEBS $J$ 2016; 284: $27-41$.

22. Corti F, Finetti F, Ziche M, Simons M. The syndecan-4/protein kinase Calpha pathway mediates prostaglandin E2-induced extracellular regulated kinase (ERK) activation in endothelial cells and angiogenesis in vivo. J Biol Chem 2013; 288: 12712-12721.

23. Das S, Majid M, Baker AB. Syndecan-4 enhances PDGF-BB activity in diabetic wound healing. Acta Biomater 2016; 42: 56-65

24. Couchman JR, Woods A. Syndecan-4 and integrins: combinatorial signaling in cell adhesion. J Cell Sci 1999; 112(Pt 20): 3415-3420.

25. Morgan MR, Humphries MJ, Bass MD. Synergistic control of cell adhesion by integrins and syndecans. Nat Rev Mol Cell Biol 2007; 8: 957-969.

26. Tan X, Zhu Y, Chen C, Chen X, Qin Y, Qu B et al. Sprouty2 suppresses epithelialmesenchymal transition of human lens epithelial cells through blockade of Smad2 and ERK1/2 pathways. PLOS ONE 2016; 11: e0159275.

27. Lovicu FJ, McAvoy JW. FGF-induced lens cell proliferation and differentiation is dependent on MAPK (ERK1/2) signalling. Development 2001; 128: 5075-5084.

28. Kubben F, Peeters-Haesevoets A, Engels L, Baeten C, Schutte B, Arends $\mathrm{J}$ et al. Proliferating cell nuclear antigen (PCNA): a new marker to study human colonic cell proliferation. Gut 1994; 35: 530-535.

29. Vermeulen K, Berneman ZN, Van Bockstaele DR. Cell cycle and apoptosis. Cell prolif 2003; 36: $165-175$

30. Lundberg AS, Weinberg RA. Functional inactivation of the retinoblastoma protein requires sequential modification by at least two distinct cyclin-cdk complexes. Mol Cell Biol 1998; 18: 753-761.

31. Blagosklonny MV, Pardee AB. The restriction point of the cell cycle. Cell Cycle 2002; 1 : 103-110.

32. Goetz R, Mohammadi M. Exploring mechanisms of FGF signalling through the lens of structural biology. Nat Rev Mol Cell Biol 2013; 14: 166-180.

33. Gesbert F, Sellers WR, Signoretti S, Loda M, Griffin JD. BCR/ABL regulates expression of the cyclin-dependent kinase inhibitor p27Kip1 through the phosphatidylinositol 3-Kinase/ AKT pathway. J Biol Chem 2000; 275: 39223-39230.

34. Zhou BP, Liao Y, Xia W, Spohn B, Lee M-H, Hung M-C. Cytoplasmic localization of p21Cip1/WAF1 by Akt-induced phosphorylation in HER-2/neu-overexpressing cells. Nat Cell Biol 2001; 3: 245-252.
35. Torii S, Yamamoto T, Tsuchiya Y, Nishida E. ERK MAP kinase in G1 cell cycle progression and cancer. Cancer Sci 2006; 97: 697-702.

36. Meloche S, Pouysségur J. The ERK $1 / 2$ mitogen-activated protein kinase pathway as a master regulator of the G1-to S-phase transition. Oncogene 2007; 26: 3227-3239.

37. Boilly B, Vercoutter-Edouart A, Hondermarck H, Nurcombe V, Le Bourhis X. FGF signals for cell proliferation and migration through different pathways. Cytokine Growth Factor Rev 2000; 11: 295-302

38. Jang E, Albadawi H, Watkins MT, Edelman ER, Baker AB. Syndecan-4 proteoliposomes enhance fibroblast growth factor-2 (FGF-2)-induced proliferation, migration, and neovascularization of ischemic muscle. Proc Natl Acad Sci USA 2012; 109: 1679-1684

39. Midwood KS, Valenick LV, Hsia HC, Schwarzbauer JE. Coregulation of fibronectin signaling and matrix contraction by tenascin-C and syndecan-4. Mol Biol Cell 2004; 15 5670-5677.

40. Echtermeyer F, Streit M, Wilcox-Adelman S, Saoncella S, Denhez F, Detmar M et al. Delayed wound repair and impaired angiogenesis in mice lacking syndecan-4. J Clin Invest 2001; 107: R9-R14.

41. McLean SM, Mathew MR, Kelly JB, Murray SB, Bennett HG, Webb LA et al. Detection of integrins in human cataract lens epithelial cells and two mammalian lens epithelial cell lines. Br J Ophthalmol 2005; 89: 1506-1509.

42. Beck R, Nebe B, Guthoff R, Rychly J. Inhibition of lens epithelial cell adhesion by the calcium antagonist Mibefradil correlates with impaired integrin distribution and organization of the cytoskeleton. Graefes Arch Clin Exp Ophthalmol 2001; 239: 452-458.

43. Ishiguro K, Kadomatsu K, Kojima T, Muramatsu H, Tsuzuki S, Nakamura E et al. Syndecan4 deficiency impairs focal adhesion formation only under restricted conditions. J Biol Chem 2000; 275: 5249-5252.

44. Xiao W, Chen X, Li W, Ye S, Wang W, Luo L et al. Quantitative analysis of injury-induced anterior subcapsular cataract in the mouse: a model of lens epithelial cells proliferation and epithelial-mesenchymal transition. Sci Rep 2015; 5: 8362.

45. Mamuya FA, Wang Y, Roop VH, Scheiblin DA, Zajac JC, Duncan MK. The roles of $\alpha \mathrm{V}$ integrins in lens EMT and posterior capsular opacification. J Cell Mol Med 2014; 18 656-670.

46. Yoshino M, Kurosaka D, Obazawa M, Takayama F. Presence of alpha 5 beta 1 integrin and fibronectin in the anterior subcapsular cataract. Nippon Ganka Gakkai Zasshi 2001; 105 83-87.

47. Walker J, Menko AS. Integrins in lens development and disease. Exp Eye Res 2009; 88: 216-225

48. Gallo R, Kim C, Kokenyesi R, Adzick NS, Bernfield M. Syndecans-1 and-4 are induced during wound repair of neonatal but not fetal skin. J Invest Dermatol 1996; 107 676-683.

49. Couchman JR. Syndecans: proteoglycan regulators of cell-surface microdomains? Nat Rev Mol Cell Biol 2003; 4: 926-937.

50. Verdoorn C, de Lavalette VWR, Dalma-Weizhausz J, Orr GM, Sorgente N, Ryan SJ. Cellula migration, proliferation, and contraction: an in vitro approach to a clinical problem proliferative vitreoretinopathy. Arch Ophthalmol 1986; 104: 1216-1219.

51. Oh ES, Woods A, Couchman JR. Syndecan-4 proteoglycan regulates the distribution and activity of protein kinase C. J Biol Chem 1997; 272: 8133-8136.

52. Keum E, Kim Y, Kim J, Kwon S, Lim Y, Han I et al. Syndecan-4 regulates localization, activity and stability of protein kinase C-alpha. Biochem J 2004; 378(Pt 3): 1007-1014.

53. Zhang W, Liu HT. MAPK signal pathways in the regulation of cell proliferation in mammalian cells. Cell Res 2002; 12: 9-18.

54. Partovian C, Ju R, Zhuang ZW, Martin KA, Simons M. Syndecan-4 regulates subcellular localization of mTOR complex2 and Akt activation in a PKCalpha-dependent manner in endothelial cells. Mol Cell 2008; 32: 140-149.

55. Ju R, Simons M. Syndecan 4 regulation of PDK1-dependent Akt activation. Cell Signal 2013 25: $101-105$.

56. Matsui Y, Ikesue M, Danzaki K, Morimoto J, Sato M, Tanaka S et al. Syndecan-4 prevents cardiac rupture and dysfunction after myocardial infarction. Circ Res 2011; 108 : 1328-1339.

57. Couchman JR. Transmembrane signaling proteoglycans. Annu Rev Cell Dev Biol 2010; 26 89-114

58. Woods A, Couchman JR. Syndecan-4 and focal adhesion function. Curr Opin Cell Biol 2001; 13: $578-583$.

59. Wilcox-Adelman SA, Denhez F, Goetinck PF. Syndecan-4 modulates focal adhesion kinase phosphorylation. J Biol Chem 2002; 277: 32970-32977.

60. Rusnati M, Tanghetti E, Dell'Era P, Gualandris A, Presta M. alphavbeta3 integrin mediates the cell-adhesive capacity and biological activity of basic fibroblast growth factor (FGF-2) in cultured endothelial cells. Mol Biol Cell 1997; 8: 2449-2461.

61. Rozo M, Li L, Fan CM. Targeting beta1-integrin signaling enhances regeneration in aged and dystrophic muscle in mice. Nat Med 2016; 22: 889-896.

62. Labropoulou VT, Skandalis SS, Ravazoula P, Perimenis P, Karamanos NK, Kalofonos HP et al. Expression of syndecan-4 and correlation with metastatic potential in testicular germ cell tumours. Biomed Res Int 2013; 2013: 214864.

63. Na KY, Bacchini P, Bertoni F, Kim YW, Park YK. Syndecan-4 and fibronectin in osteosarcoma. Pathology 2012; 44: 325-330.

64. Baba F, Swartz $K$, van Buren $R$, Eickhoff J, Zhang $Y$, Wolberg $W$ et al. Syndecan-1 and syndecan- 4 are overexpressed in an estrogen receptor-negative, highly proliferative breast carcinoma subtype. Breast Cancer Res Treat 2006; 98: 91-98. 
65. Ikeda H, Hideshima T, Fulciniti M, Lutz RJ, Yasui H, Okawa Y et al. The monoclonal antibody nBT062 conjugated to cytotoxic Maytansinoids has selective cytotoxicity against CD138positive multiple myeloma cells in vitro and in vivo. Clin Cancer Res 2009; 15: 4028-4037.

66. Orecchia P, Conte R, Balza E, Petretto A, Mauri P, Mingari MC et al. A novel human antisyndecan-1 antibody inhibits vascular maturation and tumour growth in melanoma. Eur $J$ Cancer 2013; 49: 2022-2033.

67. Rousseau C, Ferrer L, Supiot S, Bardies M, Davodeau F, Faivre-Chauvet A et al. Dosimetry results suggest feasibility of radioimmunotherapy using anti-CD138 (B-B4) antibody in multiple myeloma patients. Tumour Biol 2012; 33: 679-688.

68. Martinez G, de longh RU. The lens epithelium in ocular health and disease. Int J Biochem Cell Biol 2010; 42: 1945-1963.

69. Jarrin M, Pandit T, Gunhaga L. A balance of FGF and BMP signals regulates cell cycle exit and Equarin expression in lens cells. Mol Biol Cell 2012; 23: 3266-3274.

70. McAvoy JW, Chamberlain CG, de longh RU, Richardson NA, Lovicu FJ. The role of fibroblast growth factor in eye lens development. Ann N Y Acad Sci 1991; 638: 256-274.

71. Tanaka T, Saika S, Ohnishi Y, Ooshima A, McAvoy JW, Liu CY et al. Fibroblast growth factor 2: roles of regulation of lens cell proliferation and epithelial-mesenchymal transition in response to injury. Mol Vis 2004; 10: 462-467.

72. Nibourg LM, Gelens E, Kuijer R, Hooymans JM, van Kooten TG, Koopmans SA. Prevention of posterior capsular opacification. Exp Eye Res 2015; 136: 100-115.

73. Wormstone IM, Wang L, Liu CS. Posterior capsule opacification. Exp Eye Res 2009; 88: 257-269.

74. Chen C, Zhu Y, Lin Y, Liu Z, Wu M, Li D et al. Suppression of retinal pigment epithelial cell proliferation, migration and epithelial-mesenchymal transition by proteasome inhibition, a potential defense against proliferative vitreoretinopathy. Invest Ophthalmol Vis Sci 2013; 54 6254-6254.

75. Zhang Y, Morgan R, Chen C, Cai Y, Clark E, Khan WN et al. Mammary-tumor-educated B cells acquire LAP/TGF-beta and PD-L1 expression and suppress anti-tumor immune responses. Int Immunol 2016; 28: 423-433.
76. Ichihashi YT, Yamaoka T, Ohmori T, Ohba M. Up-regulation of Syndecan-4 contributes to TGF- $\beta 1$-induced epithelial to mesenchymal transition in lung adenocarcinoma A549 cells. Biochem Biophys Rep 2016; 5: 1-7.

77. Scarpellini A, Huang L, Burhan I, Schroeder N, Funck M, Johnson TS et al. Syndecan-4 knockout leads to reduced extracellular transglutaminase-2 and protects against tubulointerstitial fibrosis. J Am Soc Nephrol 2014; 25: 1013-1027.

78. Ju R, Zhuang ZW, Zhang J, Lanahan AA, Kyriakides T, Sessa WC et al. Angiopoietin-2 secretion by endothelial cell exosomes: regulation by the phosphatidylinositol 3-kinase (PI3K)/Akt/endothelial nitric oxide synthase (eNOS) and syndecan-4/syntenin pathways. J Biol Chem 2014; 289: 510-519.

79. Ishiguro K, Kadomatsu K, Kojima T, Muramatsu H, Iwase M, Yoshikai Y et al. Syndecan-4 deficiency leads to high mortality of lipopolysaccharide-injected mice. J Biol Chem 2001; 276: 47483-47488.

(c) (i) Cell Death and Disease is an open-access journal published by Nature Publishing Group. This work is licensed under a Creative Commons Attribution 4.0 International License. The images or other third party material in this article are included in the article's Creative Commons license, unless indicated otherwise in the credit line; if the material is not included under the Creative Commons license, users will need to obtain permission from the license holder to reproduce the material. To view a copy of this license, visit http://creativecommons.org/licenses/by/4.0/

(C) The Author(s) 2017

Supplementary Information accompanies this paper on Cell Death and Disease website (http://www.nature.com/cddis) 